Technical report on simulations results and systems intercomparison 


\title{
Technical report on simulations results and systems intercomparison
}

Chiara Dipasquale ${ }^{1}$ Roberto Fedrizzi ${ }^{1}$ Valeria Palomba² Alex Thür $^{3}$

DagmarJähnig ${ }^{4}$

June 2018

Task 53 / Report B5, http://dx.doi.org/10.18777/ieashc-task53-2019-0010

\author{
1Institution EURAC Research \\ Address viale Druso, 1 - 39100, Bolzano - Italy \\ Phone +393387311504 \\ e-mail_roberto.fedrizzi@eurac.edu
}

Contributors

Valeria Palomba (CNR), Alex Thür (UIBK), DagmarJaehnig (AEE INTEC) 


\section{Contents}

Contents

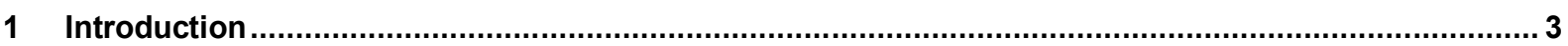

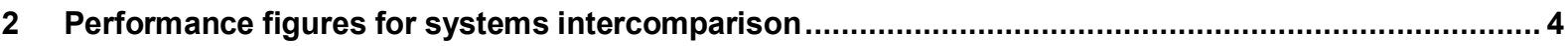

2.1 Performance indicators for heating and cooling generation units................................................ 4

2.2 Performance indicators for heating and cooling (generation and distribution) systems....................... 5

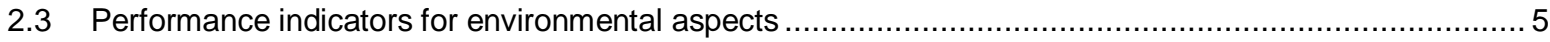

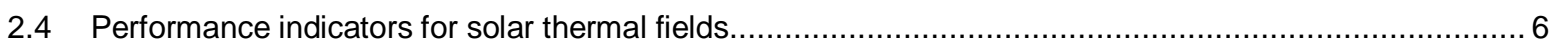

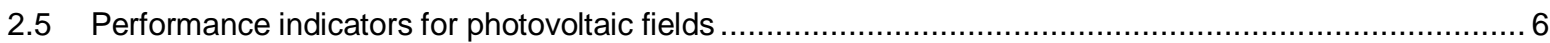

3 Simulation results for a Single-Family House reference building from the iNSPiRe project................. 7

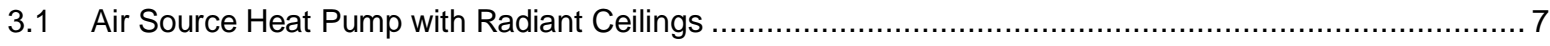

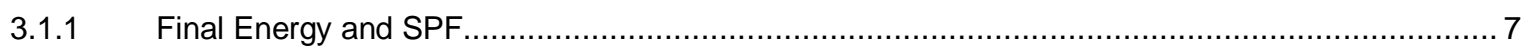

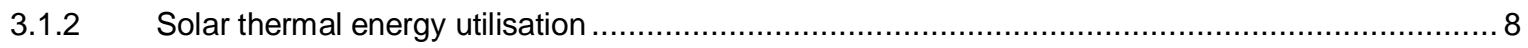

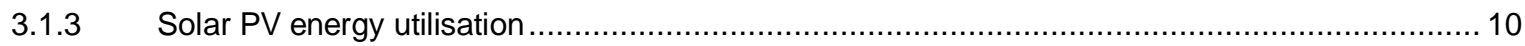

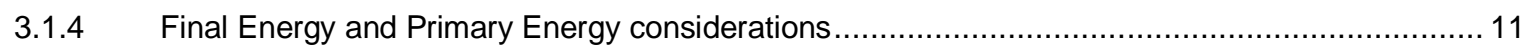

4 Simulation results for a Multi Family House reference building from the iNSPiRe project ................. 15

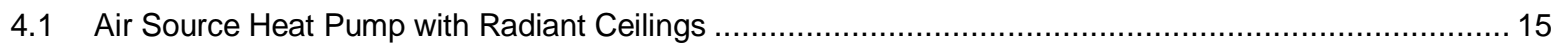

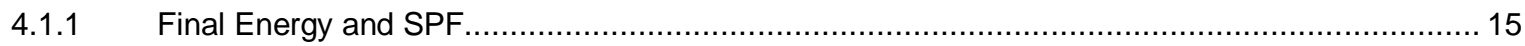

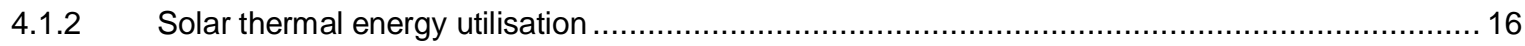

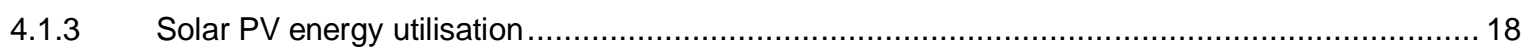

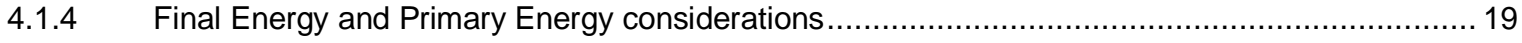

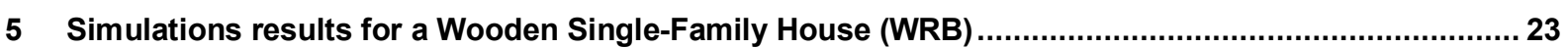

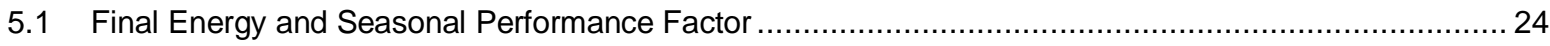

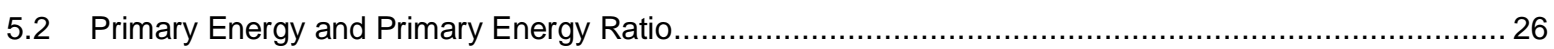

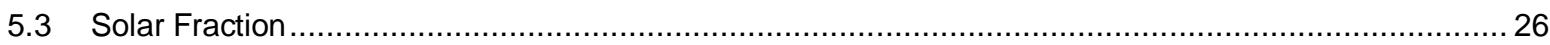

6 Simulations results for a Single-Family House - TheBat building .................................................28

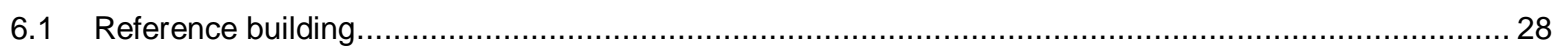

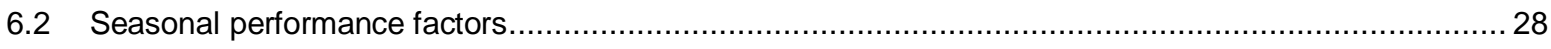

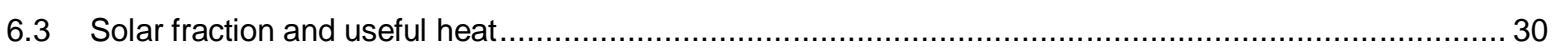

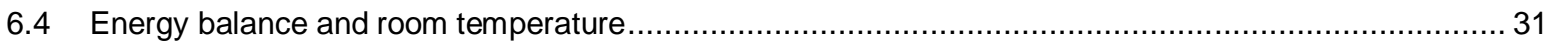

7 Simulations results for a Reference Multi Family House from the Project HVACviaFaçade................. 33

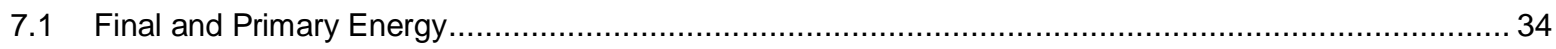

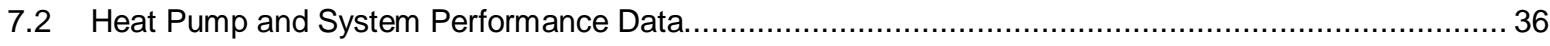

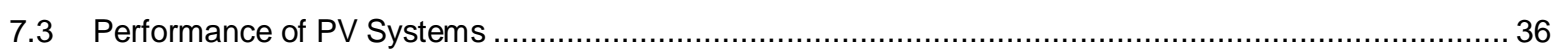

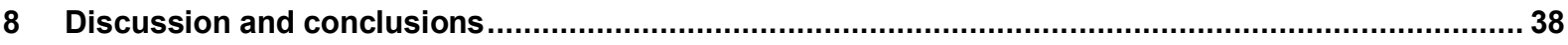

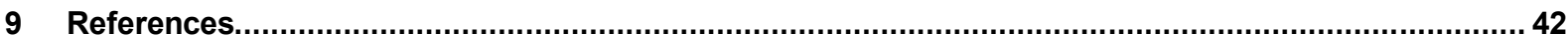




\section{Introduction}

The use of solar technologies for covering heating and cooling loads can assume different configurations. In deliverable B3, a number of this kind of heating \& cooling systems are described. These systems are installed in residential buildings described in the deliverable B1: single and multi-family houses located in different climates throughout Europe. Systems sizing and control strategies are reported in B4.

This document reports on the results obtained by dynamic simulations of the abovementioned cases and aims at giving an overview of possible applications and performance. In particular, section 2 defines the performance indicators used in all the examples to describe the HVAC system behaviour. They refer on single generation devices, like seasonal COP and EER, and on the whole system as final energy and seasonal performance factor. Performance of photovoltaic (PV) and solar thermal systems (ST) are assessed through solar fraction, solar yield, produced and self-consumed energy. The environmental impact of the presented cases is evaluated through primary energy and primary energy ratio.

The first two reported examples investigate the combination of different HVAC system layouts used under different working conditions and climates. The presence of photovoltaic or/and solar thermal systems is taken into account and in this report highlighted. In particular, results presented in chapter 3 refer to a single family house, while chapter 4 refers to multi-family houses. The considered HVAC system is composed of an air-towater heat pump with radiant ceilings.

The third case analyses an adsorption chiller system with compound parabolic concentrator collectors. Solar energy is used for heating and DHW production during wintertime and for cooling production during summer. A gas boiler is used as back-up when solar energy is not enough. Results on system performance in different locations are reported.

The fourth case studies the coupling of a geothermal heat pump with desuperheater with two PV field and storage sizes. Different control strategies are studied for increasing the self-consumption of electricity PVproduced. The base case of self-consumed energy is compared with the solution of overheating the thermal storage tank or the thermal activated building structure, or both.

Finally, the fifth case compares three different system configurations where i) a centralized heat pump, ii) one heat pump per apartment and iii) an electric heater per apartment are coupled with a PV system. Two buildings energy levels are studied, 15 and $30 \mathrm{kWh} / \mathrm{m}^{2} \cdot \mathrm{y}$. 


\section{Performance figures for systems intercomparison}

The performance indicators used for assessing the behaviour of the systems analysed in this document are summarized in the following paragraphs. The indicators are divided by energy, environment and solar energy systems performance. The energy indicators refer to single components (SCOP, SEER) and to the entire system (seasonal performance factor - SPF and final energy - FE); environmental indicators are intended as Primary Energy use - PE and Primary Energy Ratio - PER; solar energy systems performance are assessed in terms of solar fraction - SF for thermal systems and of energy production and self-consumption for PV.

\subsection{Performance indicators for heating and cooling generation units}

The performance of the heating and cooling $(\mathrm{H} \& \mathrm{C})$ generation units are reported in terms of:

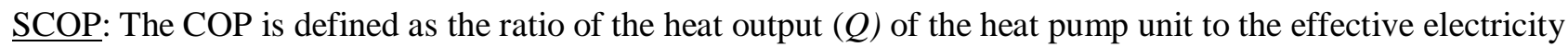
input $(E)$ to the unit for a stationary operating condition. In this case, the ratio is calculated based on the average seasonal values both thermal and electric. SCOP is calculated for the two different uses, domestic hot water (DHW) production and space heating $(\mathrm{SH})$.

$$
\begin{gathered}
S C O P_{D H W}=Q_{D H W} / E_{D H W} \\
S C O P_{S H}=Q_{S H} / E_{S H} \\
S C O P_{t o t}=\left(Q_{D H W}+Q_{S H}\right) /\left(E_{D H W}+E_{S H}\right)
\end{gathered}
$$

SEER: The EER is defined as the ratio of the cold output $(Q)$ of the reversible heat pump unit to the effective electricity input $(E)$ to the unit for a stationary operating condition. In this case, the ratio is calculated based on the average seasonal values both thermal and electric. SEER is calculated for the energy used for space cooling (SC).

$$
S E E R_{S C}=Q_{S C} / E_{S C}
$$

The control volume for the assessment of the above energy fluxes refers to the unit, meaning that we consider the electricity needed to run the heat pump compressor, backup electric heater and fan (the latter in case of airto-water heat pump), while the electricity used to drive any pumps is not accounted for. 


\subsection{Performance indicators for heating and cooling (generation and distribution) systems}

The above performance figures can be used also when moving the study from the single unit to the entire generation and distribution system.

In this case, the electricity consumption figures also account for the energy used by all the pumps, valves and control unit, as well as the electricity used by the mechanical ventilation. The delivered energy to the building accounts for the thermal losses of the system (pipes, heat exchanger...).

SPF: SEASONAL PERFORMANCE FACTOR refers to the ratio between the thermal energy delivered to the building and the whole electricity used for that purpose. This can be referred to space heating, space cooling, DHW or total (mechanical ventilation included).

FINAL ENERGY USE: for electricity driven systems, the FE equals the electricity used to drive the HVAC systems, while for gas or biomass driven ones, the FE equals the fuel higher calorific value by its mass consumption.

\subsection{Performance indicators for environmental aspects}

Environmental aspects are accounted for in terms of Primary Energy ad Primary Energy Ratio. These indicators are also used in order to compare systems and technologies in terms of their environmental impact, although the different energy source.

PRIMARY ENERGY USE: gives information on the consumption of non-renewable energy sources for the provision of useful energy output of the system. Note that this does not account for the production, distribution, installation and end-of-life disposal of the HVAC system itself. It is a figure which considers the depletion of limited energy resources contained in e.g. fossil fuels.

This figure is calculated by multiplying the consumed final energy for the $\mathrm{CED}_{\mathrm{NRE}}-$ Cumulative Energy Demand (CED), non-renewable: it quantifies the non-renewable primary energy used to provide the final energy, including the energy used for construction of the electric grid and power plants. This indicator accounts for the primary energy from fossil, nuclear and primary forest resources (i.e. original forests that are destroyed and replaced by farmland) defined in terms of primary energy to final energy - $\mathrm{kWh}_{\mathrm{PE}} / \mathrm{kWh}$

$$
P E=F E * C E D_{N R E}
$$

The primary energy factor is referred to non-renewable energy and the used value is a European average for the year 2012. For certain individual countries it is larger than others and it will decrease with time as a consequence of the expected increasing RES penetration in the electricity market. Table 1 summarizes the used $\mathrm{CED}_{\mathrm{NR}}$.

Table 1 - CEDnRE for different energy carriers [4]

\begin{tabular}{|l|l|}
\hline Energy carrier & $\mathrm{CED}_{\mathrm{NRE}}\left[\mathrm{kWh}_{\mathrm{PE}} / \mathrm{kWh}_{\mathrm{FE}}\right]$ \\
\hline Electricity & 2.878 \\
\hline Gas & 1.194 \\
\hline
\end{tabular}

PRIMARY ENERGY RATIO: same calculation approach used for the SPF definition can be used for the calculation of the PER. In this case, the PE is used instead of the FE at the denominator. This allows to compute a performance figure that comprehends all the different energy uses that cannot be summed up as it is.

$$
\begin{gathered}
P E R_{D H W}=Q_{D H W} / P E_{D H W} \\
P E R_{S H}=Q_{S H} / P E_{S H} \\
P E R_{S C}=Q_{S C} / P E_{S C}
\end{gathered}
$$




$$
P E R_{t o t}=\left(Q_{D H W}+Q_{S H}+Q_{S C}\right) /\left(P E_{D H W}+P E_{S H}+P E_{S C}\right)
$$

\subsection{Performance indicators for solar thermal fields}

SOLAR FRACTION: is defined as the percentage of DHW, heating and cooling demand that is covered by solar thermal energy.

$$
\begin{gathered}
S F_{D H W}=Q_{S T, D H W} / Q_{D H W} \\
S F_{S H}=Q_{S T, S H} / Q_{S H} \\
S F_{t o t}=\left(Q_{\mathrm{ST}, D H W}+Q_{\mathrm{ST}, S H}\right) /\left(Q_{D H W}+Q_{S H}\right) \\
S F_{S C}=\left(Q_{\mathrm{ST}, \mathrm{SC}} \cdot \mathrm{EER}\right) / Q_{S C}=\mathrm{Q}_{\mathrm{ST}, \mathrm{SC}} /\left(\mathrm{Q}_{\mathrm{ST}, \mathrm{SC}}+\mathrm{Q}_{\mathrm{gas}}\right)
\end{gathered}
$$

In particular for DHW and heating demands, $Q_{S T}$ is the net solar thermal energy employed for covering the DHW or heating demand, detracted of thermal losses along the pipelines and the thermal storage. The computation of this figure has an uncertainty when all solar thermal energy is conveyed to a unique solar storage tank, and then used both for DHW preparation and for space heating.

Space cooling covered by solar energy can be calculated by multiplying the energy provided by solar collectors for the machine EER. In other terms, solar fraction for cooling is the percentage of solar energy used by the machine over the total consumed energy (solar thermal collectors + gas).

\subsection{Performance indicators for photovoltaic fields}

In case a PV system is installed in a system, the previous descried figures account for the PV electricity produced and instantaneously consumed by the H\&C system: the PV electricity is subtracted by the electricity consumption if it is produced when H\&C system operates. In many cases, this is a small fraction of the total PV production. Therefore, the following cases show the total PV electricity consumption, how much of this electricity is self-consumed and how much is fed into the grid. Note that the self-consumption is based on a time step of 1 hour (consumption as well as PV electricity production).

PV SELF-CONSUMPTION RATIO: represents the ratio between the produced PV energy and self-consumed over the total PV production.

$$
P V_{\text {self }}=\frac{P V_{\text {consumed }}}{P V_{\text {production }}}
$$

SOLAR FRACTION: is the percentage of space heating or cooling covered by solar energy over the total demand. In case of heat pumps, the numerator can be intended as the PV energy used for covering heating or cooling demand multiplied by the COP or EER. In other terms for each energy use, the solar fraction represents the percentage of PV electricity over the total consumed energy (PV + grid).

$$
S F_{S \mathrm{H}}=\left(\mathrm{E}_{\mathrm{PV}, \mathrm{SH}} \cdot \mathrm{COP}_{\mathrm{SH}}\right) /_{Q_{S \mathrm{H}}}=\mathrm{E}_{\mathrm{PV}, \mathrm{SH}} /\left(\mathrm{E}_{\mathrm{PV}, \mathrm{SH}}+\mathrm{E}_{\mathrm{grid}, \mathrm{SH}}\right) S F_{S \mathrm{C}}=\left(\mathrm{E}_{\mathrm{PV}, \mathrm{SC}} \cdot \mathrm{EER}_{\mathrm{SC}}\right) /_{Q_{S C}}=\mathrm{E}_{\mathrm{PV}, \mathrm{SC}} /\left(\mathrm{E}_{\mathrm{PV}, \mathrm{SC}}+\mathrm{E}_{\text {grid }, \mathrm{SC}}\right)
$$




\section{Simulation results for a Single-Family House reference building from the iNSPiRe project}

The present chapter reports on a selection of cases simulated within the project FP7 iNSPiRe. The whole set of simulations can be found in the reports and database at the link: http://inspirefp7.eu/target-buildingsimulation-data/. Reference buildings geometry and physics are described in the report B1, HVAC system layout and simulated variants can be found in B3 while the adopted control strategies are included in B4.

Briefly, the reference building consists of a single-family house (SFH) developed in two floors for a total surface of around $100 \mathrm{~m}^{2}$. Simulations are run for seven locations around Europe and four heating demand energy levels, $15,25,45$ and $70 \mathrm{kWh} / \mathrm{m}^{2} \cdot \mathrm{y}$. The energy plant layout consists of a generation device chosen between an air-to-water heat pump, ground-to-water heat pump, condensing boiler or pellet boiler coupled with radiators or fan coils or radiant ceilings. In addition to this, a solar thermal (ST) system and a photovoltaic (PV) system with different field sizes and slopes are analysed.

For the sake of simplicity, only a selection of the collected results is presented in the following. A focus on the contribution that solar technologies can give on the final energy consumption and energy plant efficiency is underlined. Table 2 reports the energy use for space heating, space cooling, DHW production and ventilation of a Single Family House (SFH) located in the Nordic climate, reference weather conditions of Stockholm, and in the Mediterranean, reference weather conditions of Rome. As specified in B1, mechanical ventilation is foreseen only in the most efficient energy levels.

Table 2 Used energy for heating and cooling, DHW and ventilation

\begin{tabular}{cccccc}
\hline CLIMATE & $\begin{array}{c}\text { ENERGY } \\
\text { LEVEL }\end{array}$ & $\begin{array}{c}\text { SPACE } \\
\text { HEATING }\end{array}$ & $\begin{array}{c}\text { SPACE } \\
\text { COOLING }\end{array}$ & $\begin{array}{c}\text { DHW } \\
\text { PRODUCTIO } \\
\text { N }\end{array}$ & $\begin{array}{c}\text { VENTILATIO } \\
\text { N }\end{array}$ \\
\hline \multirow{2}{*}{ Nordic (Stockholm) } & {$\left[\mathrm{kWh} / \mathrm{m}^{2} \cdot \mathrm{y}\right]$} & {$\left[\mathrm{kWh} / \mathrm{m}^{2} \cdot \mathrm{y}\right]$} & {$\left[\mathrm{kWh} / \mathrm{m}^{2} \cdot \mathrm{y}\right]$} & {$\left[\mathrm{kWh} / \mathrm{m}^{2} \cdot \mathrm{y}\right]$} & {$\left[\mathrm{kWh} / \mathrm{m}^{2} \cdot \mathrm{y}\right]$} \\
& 15 & $\mathbf{2 1 . 5}$ & $\mathbf{1 1 . 8}$ & 21.7 & 4.2 \\
& 25 & $\mathbf{2 3 . 6}$ & $\mathbf{1 1 . 3}$ & 21.7 & 4.2 \\
& 45 & $\mathbf{5 1 . 3}$ & $\mathbf{7 . 4}$ & 21.7 & 4.2 \\
& 70 & $\mathbf{7 3 . 7}$ & $\mathbf{5 . 5}$ & 21.7 & 0.0 \\
\hline Mediterranean & 15 & $\mathbf{1 6 . 2}$ & $\mathbf{3 3 . 1}$ & 21.8 & 4.2 \\
(Rome) & 25 & $\mathbf{2 8 . 1}$ & $\mathbf{3 3 . 1}$ & 21.8 & 4.2 \\
& 45 & $\mathbf{5 3 . 7}$ & $\mathbf{2 5 . 7}$ & 21.8 & 0.0 \\
& 70 & $\mathbf{7 5 . 9}$ & $\mathbf{2 8 . 4}$ & 21.8 & 0.0 \\
\hline
\end{tabular}

In the coldest climate, although the use of high insulation thickness, it is not possible to reach the most efficient targeted heating demands.

In some cases, the target EL does not match with the heating demand because of the discrete values used for the insulation thickness definition and windows quality.

\subsection{Air Source Heat Pump with Radiant Ceilings}

The following results refer to an air-to-water heat pump with radiant ceilings applied to a SFH. The distribution system temperature is fixed at $35^{\circ} \mathrm{C}$ for space heating and $15^{\circ} \mathrm{C}$ for space cooling. The base case does not consider solar technologies.

\subsubsection{Final Energy and SPF}

Final energy use depends on the building energy demand and level: most performant buildings, in fact, account also for the consumption due to mechanical ventilation $\left(0.4 \mathrm{Wh} / \mathrm{m}^{3}\right.$ of exchanged fresh air).

The consumption related to the DHW becomes significantly high after renovation (in relative terms, in the order of $10-12 \mathrm{kWh} / \mathrm{m}^{2} \mathrm{y}$ ), while final energy use for cooling is significant only in the southern case. In this climate in fact, for the most energy efficient buildings $\left(15-25 \mathrm{kWh} / \mathrm{m}^{2} \mathrm{y}\right)$ final energy used for cooling has higher impact than the one employed for heating (see Figure 1). 
Especially in EL15, electricity consumption for mechanical ventilation is comparable with the consumption for heating-up the building. Larger consumption for space heating in the northernmost country is due to the lower device performance.
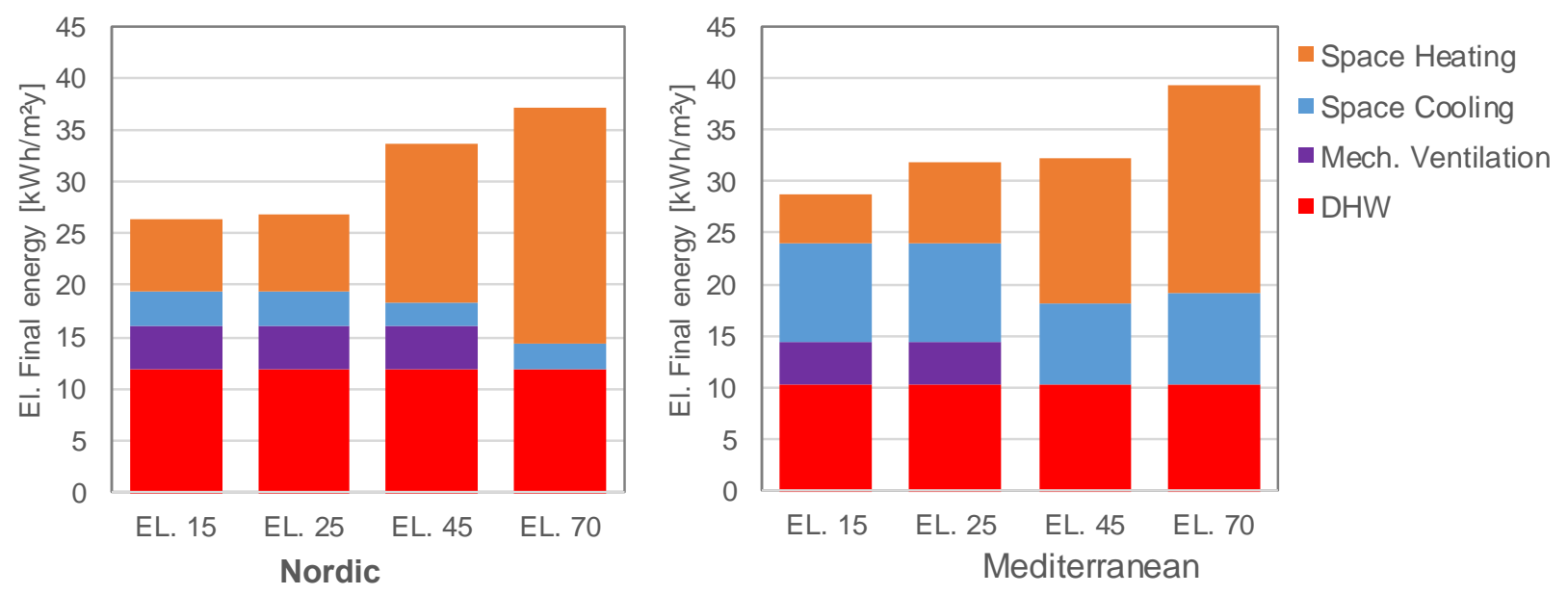

Figure 1 - Final energy distribution without solar systems and a supply water temperature of $35^{\circ} \mathrm{C}$.

In the reported cases, the SPF figures vary between 3.1 and 3.8 with respect to the space heating loads and between 3.1 and 3.6 looking at the cooling loads.

Relatively low, in all cases, are the SPFs related to the DHW preparation that range between 1.8 and 2.1 due to the thermal losses of the DHW circuit. The overall SPF values accounting for heating, cooling, DHW loads and ventilation vary in a range of 2 to 3.2, the lowest values being related to the highest envelope efficiency standards.

Table 3 - Seasonal performance Factor for DHW, space heating, space cooling and total

\begin{tabular}{|l|l|l|l|l|l|l|l|l|}
\hline & \multicolumn{3}{|l|}{ SPF - Mediterranean } & \multicolumn{2}{l|}{ SPF - Nordic } \\
\hline & DHW & $\begin{array}{l}\text { Space } \\
\text { Heating }\end{array}$ & $\begin{array}{l}\text { Space } \\
\text { Cooling }\end{array}$ & Total & DHW & $\begin{array}{l}\text { Space } \\
\text { Heating }\end{array}$ & $\begin{array}{l}\text { Space } \\
\text { Cooling }\end{array}$ & Total \\
\hline EL.15 & 2.1 & 3.4 & 3.6 & 2.9 & 1.8 & 3.1 & 3.6 & 2.0 \\
\hline EL.25 & 2.1 & 3.6 & 3.5 & 2.6 & 1.8 & 3.1 & 3.5 & 2.0 \\
\hline EL.45 & 2.1 & 3.8 & 3.3 & 3.1 & 1.8 & 3.3 & 3.2 & 2.3 \\
\hline EL.70 & 2.1 & 3.8 & 3.2 & 3.2 & 1.8 & 3.3 & 3.1 & 2.8 \\
\hline
\end{tabular}

\subsubsection{Solar thermal energy utilisation}

Solar thermal collectors are used both for space heating or/and for DHW preparation. The reported results refer to the total heating load, that is space heating and DHW being therefore the used solar energy divided by the sum of the two demands.

SF for heating production can vary from $15-42 \%$ in the Mediterranean countries (for heating demand standards from 70 to $15 \mathrm{kWh} / \mathrm{m}^{2}$ y respectively) to $10-20 \%$ in the Northern ones. Interestingly, appreciable results can be obtained also in the northern countries thanks to the longer winter season. Increasing the solar thermal field area, the exploitation of solar energy increases, achieving SF values of $70 \%$ in the Mediterranean climates, low EL and 40\% in Northern climates, low EL (see Figure 2). To be noted that in the Northern climate, the EL15 cannot be achieved with the applied envelope retrofit solutions described in B1, and the heating demand amounts to around $23 \mathrm{kWh} / \mathrm{m}^{2} \cdot \mathrm{y}$. 

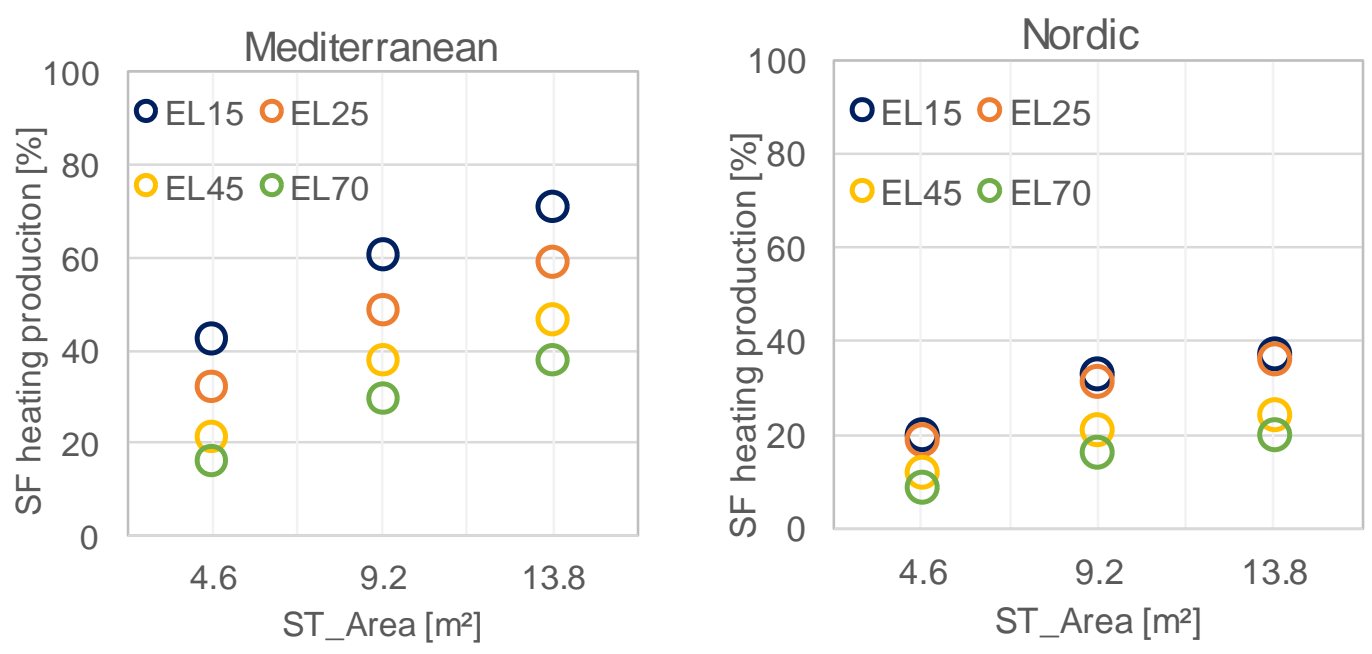

\section{Figure 2 - Solar fraction of heat production (space heating + DHW) for different solar thermal fields areas in the Mediterranean (left) and Nordic (right) climates for a SFH.}

For large collectors' areas, the overall duration of the stagnation condition is strongly influenced by the inclination. While more than 2000 hours of stagnation are found for the $30^{\circ}$ inclination, Mediterranean climate and big field area, no such condition is revealed with the installation of the collectors on the façade of the building (see Figure 3). The reported case refers to the four EL buildings.

From a purely technical point of view, the utilisation of façade mounted solar collectors is to be preferred when large solar fields are planned.
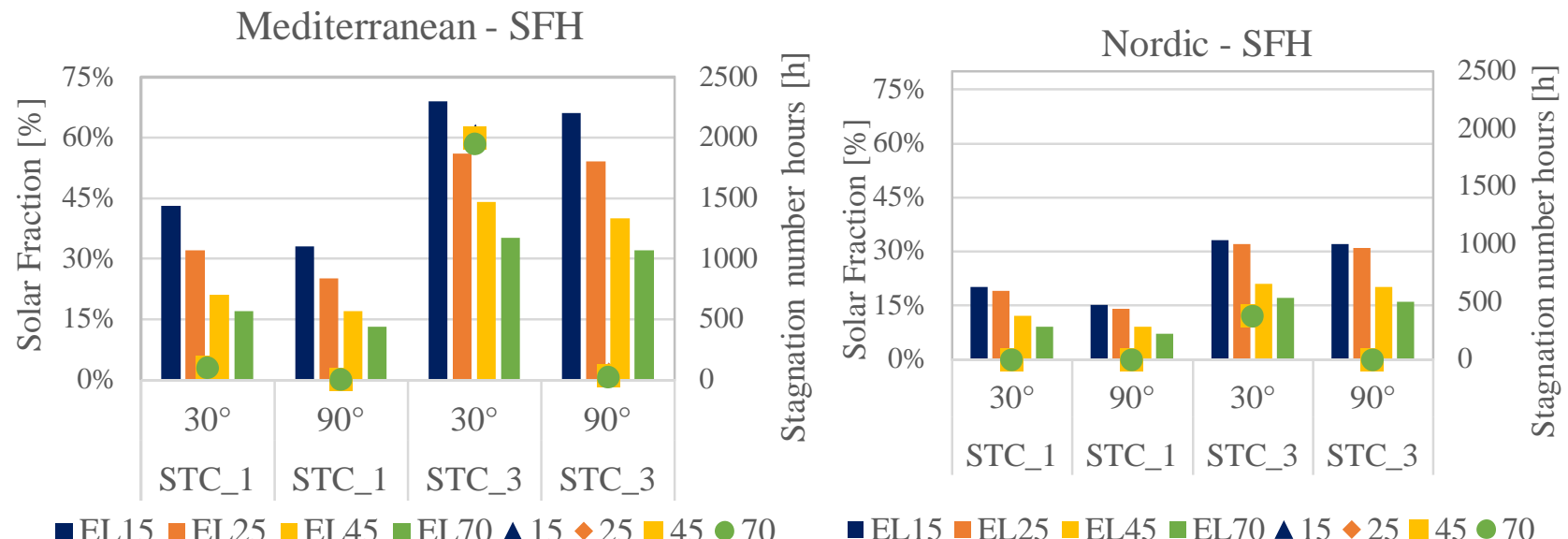

EL15 $\because$ EL25 $\because$ EL45 $\backsim$ EL70 $\Delta 15 \bullet 25 \square 45 \bullet 70$

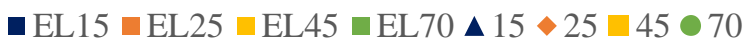

Figure 3 - Solar fraction and stagnation hours for two solar field areas and panels slope

The integration of solar thermal systems in the HVAC installations allows to decrease the total final energy consumption with an amplitude depending mainly on the climate and size of the collector field, while size of the storage tank and inclination of the surface do not have a large effect.

In northern climates, the biggest solar thermal system variant $\left(13.8 \mathrm{~m}^{2}\right)$ reduces the electricity for heating production of 28-16\% (EL15 to EL70), whereas in southern climates, the same solar field can reduce the energy consumption for heating uses by 66-38\% (EL15 to EL70) (see Figure 4). 

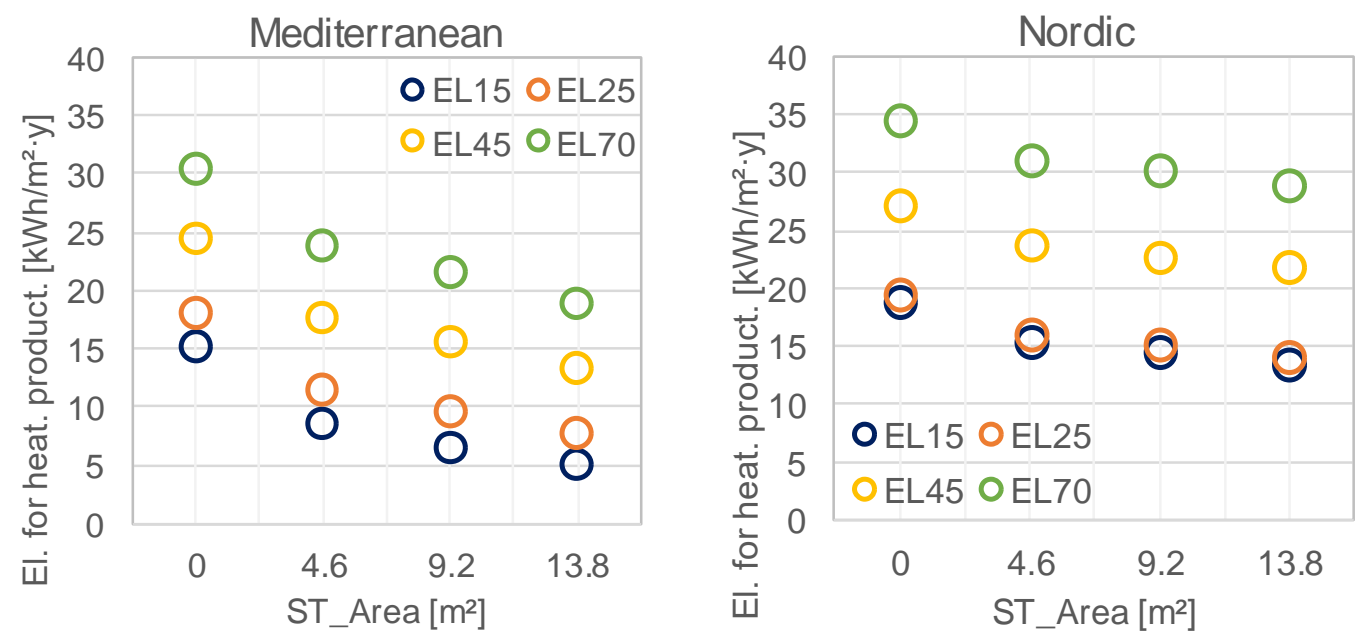

Figure 4 - Final electric energy savings with different solar thermal fields, in two locations.

\subsubsection{Solar PV energy utilisation}

Table 4shows the utilisation of the PV electricity to drive the HVAC system, lighting and appliances, and finally fed into the grid (when production exceeds all energy uses). Installing $1 \mathrm{kWp}\left(7.8 \mathrm{~m}^{2} \mathrm{PV}\right.$ field area) allows to self-consume almost all the PV electricity (around 90\%), while in the other cases, a relevant portion of the production needs to be fed into the grid.

Electric batteries are not considered in the proposed packages, thus the PV electricity can only be stored as warm water in the thermal storage tank or thermal mass of the building, but no special control algorithms were implemented to promote this.

The inclination of the panels on the façade has a minor effect on the energy self-consumption for the HVAC system.

Looking at the electricity consumption for the cooling load only, the smallest PV field can bring savings from $50-58 \%$ (EL70) to 62-68\% (EL15) in the Mediterranean and Nordic climates. Increasing the installed area, the savings increase up to around $80 \%$ for the $23.6 \mathrm{~m}^{2} \mathrm{PV}$ field.

Table 4 - Electricity consumption for cooling loads at different PV field areas

\begin{tabular}{|l|l|l|l|l|l|l|l|l|}
\hline PV field & \multicolumn{4}{l|}{ Mediterranean $\left[\mathrm{kWh} / \mathrm{m}^{2}\right]$} & \multicolumn{2}{l|}{ Nordic $\left[\mathrm{kWh} / \mathrm{m}^{2}\right]$} \\
\hline$\left[\mathrm{m}^{2}\right]$ & EL15 & EL25 & EL45 & EL70 & EL15 & EL25 & EL45 & EL70 \\
\hline 0.0 & 9.4 & 9.6 & 7.8 & 8.9 & 3.3 & 3.2 & 2.3 & 2.6 \\
\hline 7.9 & 3.5 & 4.1 & 3.0 & 4.4 & 1.1 & 1.0 & 0.9 & 1.1 \\
\hline 15.7 & 2.2 & 2.5 & 1.7 & 2.6 & 0.6 & 0.6 & 0.5 & 0.6 \\
\hline 23.6 & 1.9 & 2.1 & 1.4 & 2.2 & 0.5 & 0.5 & 0.4 & 0.4 \\
\hline
\end{tabular}




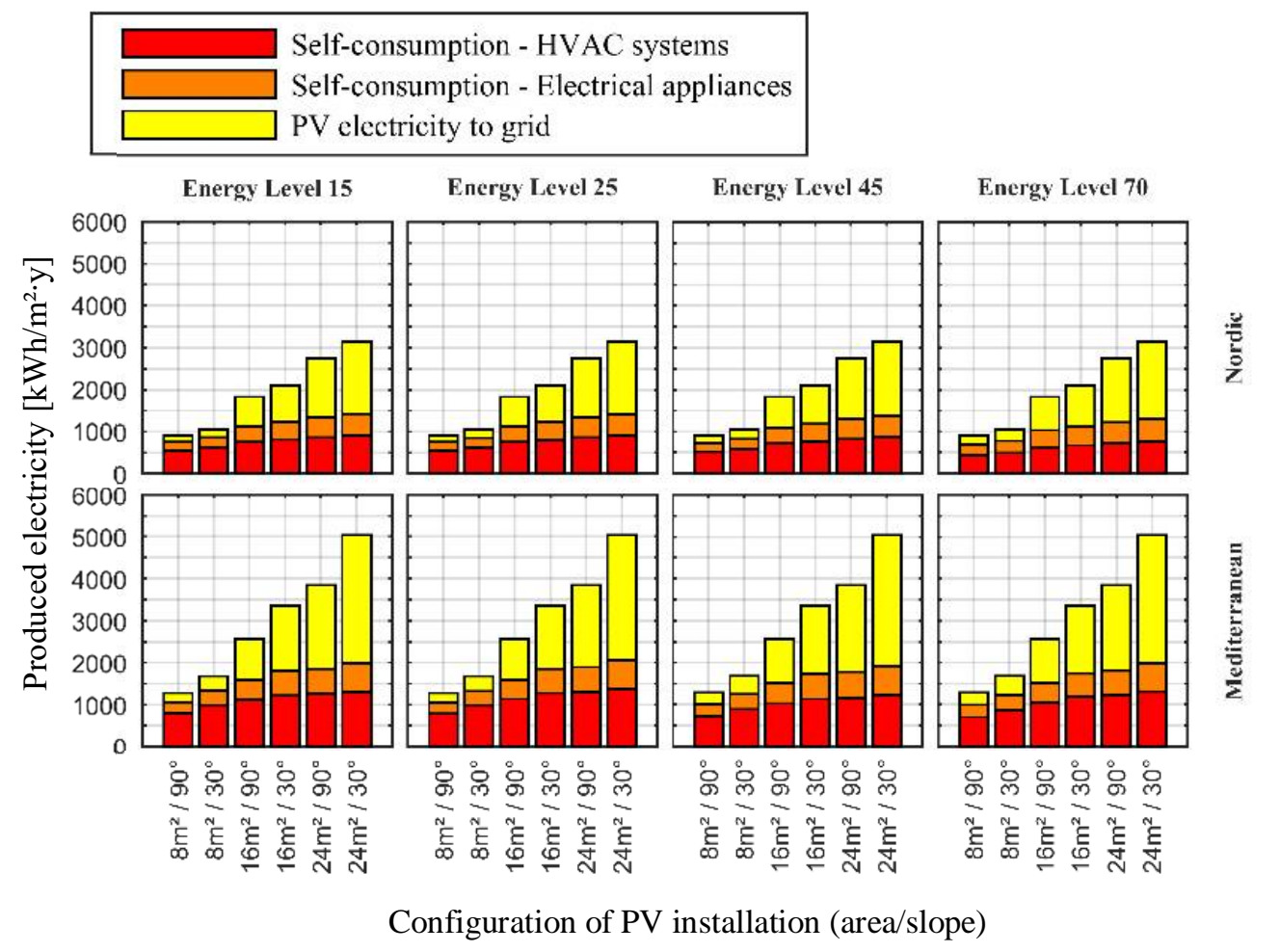

Figure 5 - Photovoltaic electricity production and self-consumption

The effect of PV fields utilisation on the buildings' specific final energy is reported in Figure 6 that accounts only for the electricity self-consumed for running the HVAC system (in order to allow for a comparison with the solar thermal cases). In line with Figure 6, the smallest PV field reduces the electricity consumption of 20$35 \%$ in the Mediterranean climate and $15-25 \%$ in the Nordic one. Doubling or tripling the PV area, the reduction is not with the same proportion as the additional generated energy is mainly fed into the grid.
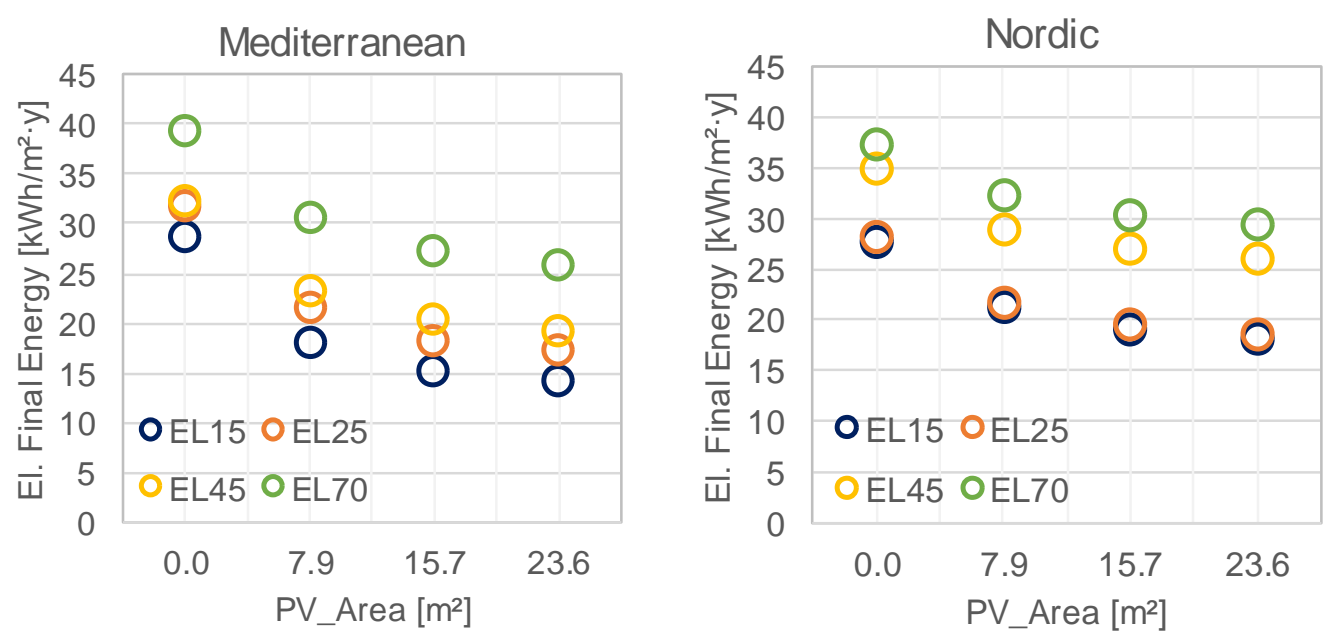

Figure 6 - Final electric energy savings without and with different PV field areas, in two locations

\subsubsection{Final Energy and Primary Energy considerations}

Figure 7 reports on the HVAC system Primary Energy consumption for space heating, cooling and DHW for two ST and PV systems sizes. The graphs compare the system performance when any solar technology is adopted (noSolar), when only a PV system (PV) or thermal collectors (ST) are used and when both technologies contribute on the improvement of the system performance (PV_ST). In the Mediterranean climate, in a building with low heating demand, a PV system with large area almost halves the primary energy consumption because acts on the cooling load reduction. However, a ST system helps to reduce by one third 
the primary energy reducing mainly the DHW consumption. In a building with EL70, instead, where the cooling and heating loads are comparable, the adoption of a solar thermal or PV system brings similar system performance. The combination of the two solar technologies allows to achieve very low primary energy consumption in a EL15 building and better performance in the EL70 too.

In the Nordic climate, the use of one of the two or both technologies has minor impact than in the southern climate, however the reduction of primary energy is consistent. The effect of the use of ST or PV, especially in buildings with higher heating demand, on the total primary energy consumption is similar.

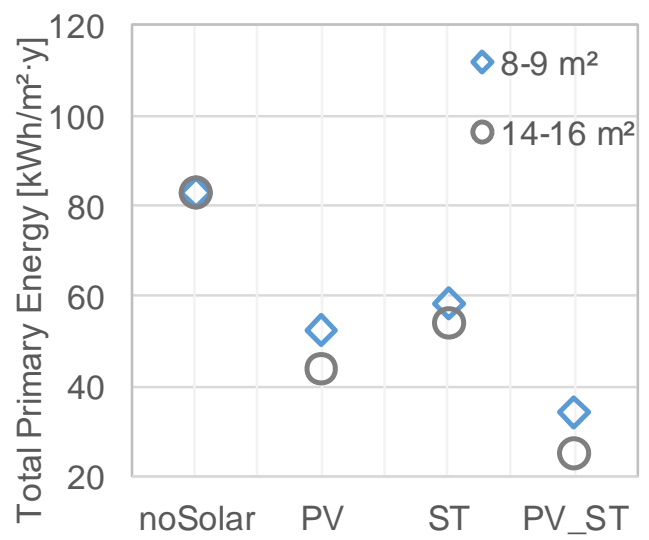

Mediterranean - EL15

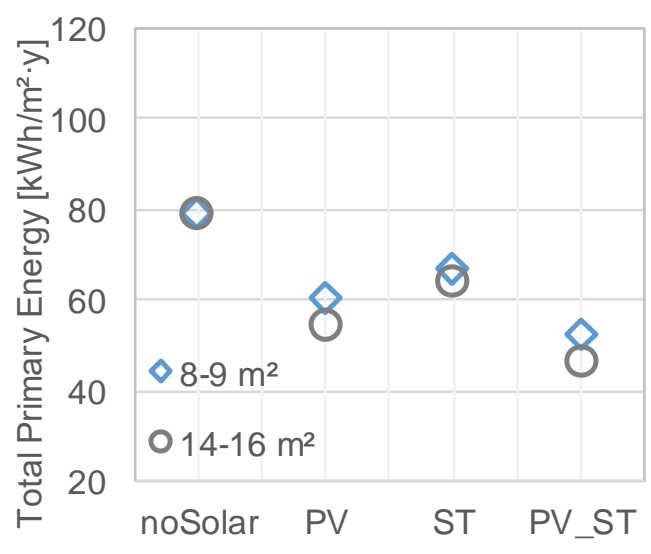

Nordic - EL15

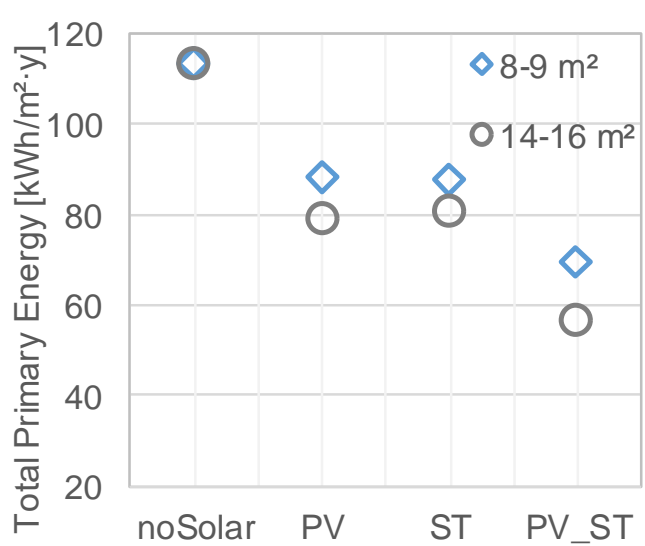

Mediterranean - EL70

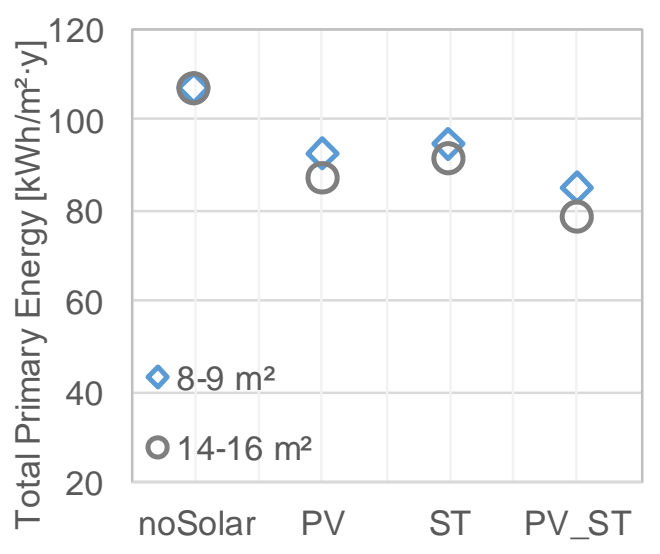

Nordic - EL70

Figure 7 - Comparison of Total Primary Energy consumption for all the building uses without any solar energy system (noSolar), with a PV system (PV), with a solar thermal system (ST) and with both technologies (PV_ST) for two heating demand energy levels of SFH located in the Mediterranean (above) and Nordic (below) climate.

Figure 8 reports the SPF values for all the uses for the above-described cases. An improvement of the SPF value is observed with one of the two solar technologies, PV or ST. In most of the cases, the combination of the two slightly increases the total SPF. 


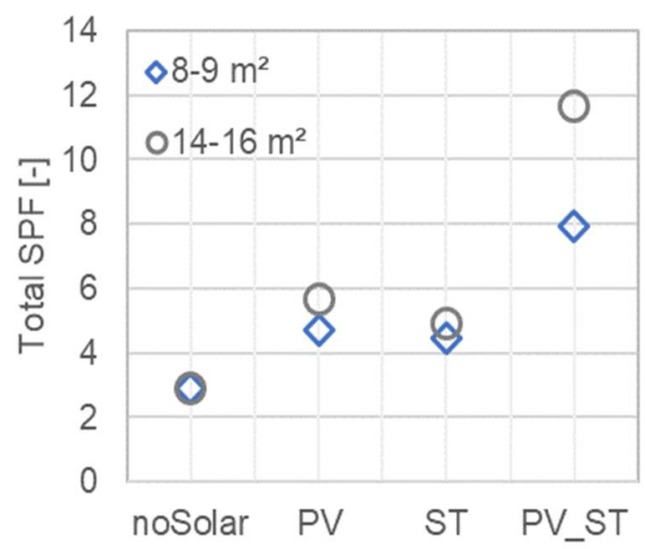

Mediterranean - EL15

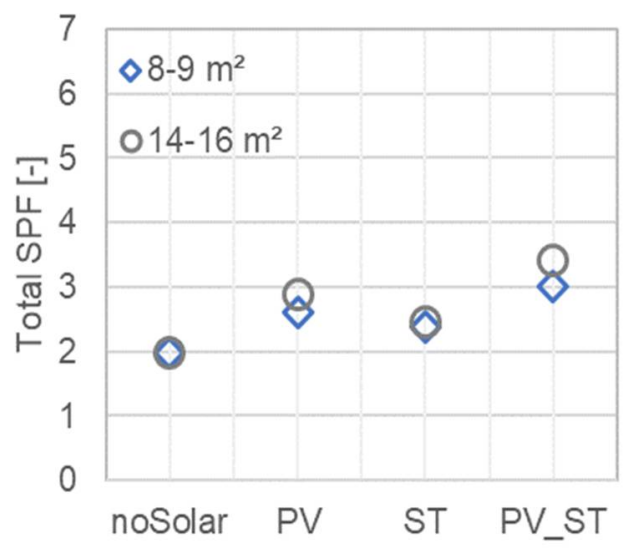

Nordic - EL15

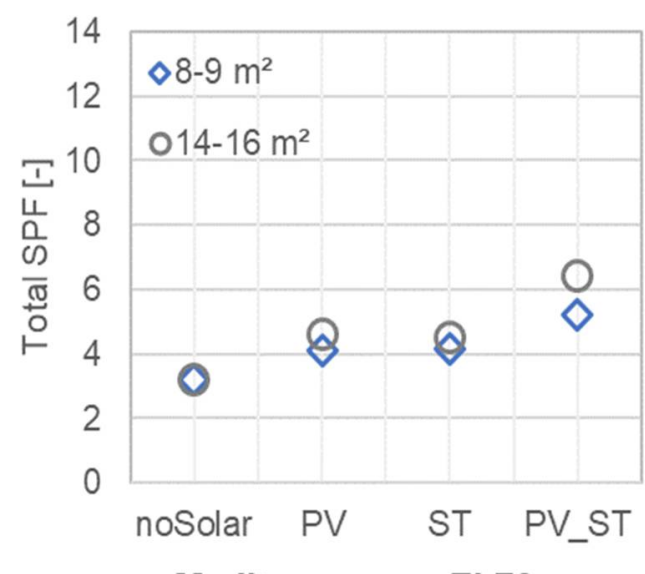

Mediterranean - EL70

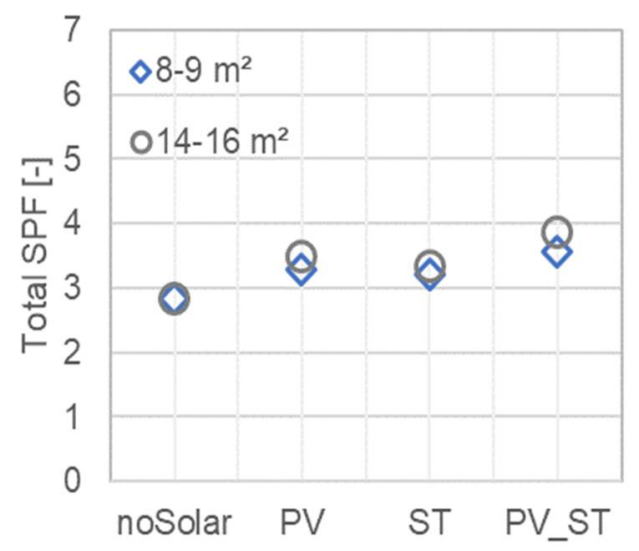

Nordic - EL70

Figure 8 - Comparison of Total SPF for all the building uses without any solar energy system (noSolar), with a PV system (PV), with a solar thermal system (ST) and with both technologies (PV_ST) for two heating demand energy levels of SFH located in the Mediterranean (above) and Nordic (below) climate

Table 5 sumarizes the primary energy ratio obtained for two building energy levels, EL15 and EL70, in the two climates. The reported results refer to the already presented different combinations of ST and PV and different solar fields areas.

Table 5 - Primary Energy Ratio for the EL15 and EL70 in the two climates for different combinations and solar fields of ST and PV

\begin{tabular}{|c|c|c|c|c|c|c|c|c|c|c|c|c|c|c|c|c|}
\hline \multirow{3}{*}{$\begin{array}{l}\text { PV- } \\
\text { ST } \\
\\
{\left[\mathrm{m}^{2}\right]}\end{array}$} & \multicolumn{8}{|c|}{ Mediterranean [-] } & \multicolumn{8}{|c|}{ Nordic [-] } \\
\hline & \multicolumn{4}{|c|}{ EL15 } & \multicolumn{4}{|c|}{ EL70 } & \multicolumn{4}{|c|}{ EL15 } & \multicolumn{4}{|c|}{ EL70 } \\
\hline & 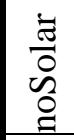 & 定 & 药 & 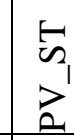 & 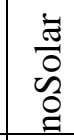 & z & 苂 & $\begin{array}{l}\tilde{n}_{1} \\
\mathrm{z}_{1}\end{array}$ & $\begin{array}{l}\text { ] } \\
0 \\
\text { ? } \\
0\end{array}$ & 足 & 穴 & $\begin{array}{l}\text { Es } \\
\text { 定 }\end{array}$ & $\begin{array}{l}\text { जี } \\
\text { ○ } \\
\mathscr{2} \\
0\end{array}$ & a & 苂 & $\begin{array}{l}\text { V } \\
z \\
z\end{array}$ \\
\hline 0.0 & 0.9 & 0.9 & 0.9 & 0.9 & 1.1 & 1.1 & 1.1 & 1.1 & 0.7 & 0.7 & 0.7 & 0.7 & 1.0 & 1.0 & 1.0 & 1.0 \\
\hline $8-9$ & 0.9 & 1.4 & 1.2 & 2.1 & $\mid 1.1$ & 1.4 & 1.4 & 1.8 & 0.7 & 0.9 & 0.8 & 1.0 & 1.0 & 1.1 & 1.1 & 1.2 \\
\hline 14-16 & 0.9 & 1.6 & 1.3 & 2.9 & 1.1 & 1.6 & 1.6 & 2.2 & 0.7 & 1.0 & 0.9 & 1.2 & 1.0 & 1.2 & 1.2 & 1.3 \\
\hline
\end{tabular}

As shown in the previous paragraph, ST or PV technologies contribute to reduce the electricity load or the thermal energy required by the system. Comparing the application of the two solar technologies with similar field areas to the same system in the two climates, it can be observed as the effect on the total final energy 
reduction does not differ from one case to the other. For this comparison, a ST field of $27.5 \mathrm{~m}^{2}$ composed by 12 panels and a $3.6 \mathrm{kWp}$ of PV system $\left(24.5 \mathrm{~m}^{2}\right)$ are considered. In the warmer climate, where the energy consumption for cooling load represents an important share of the total, the PV technology results with a slight higher electricity consumption reduction than a ST system. Increasing the heating load, from EL15 through EL70, the contribution of a ST system is bigger and bigger up to produce higher savings than a PV system.

In northern countries, the behaviour is similar as the one drawn for the Mediterranean climate. A PV system performes slightly better than a ST system, especially in low energy demanding buildings.
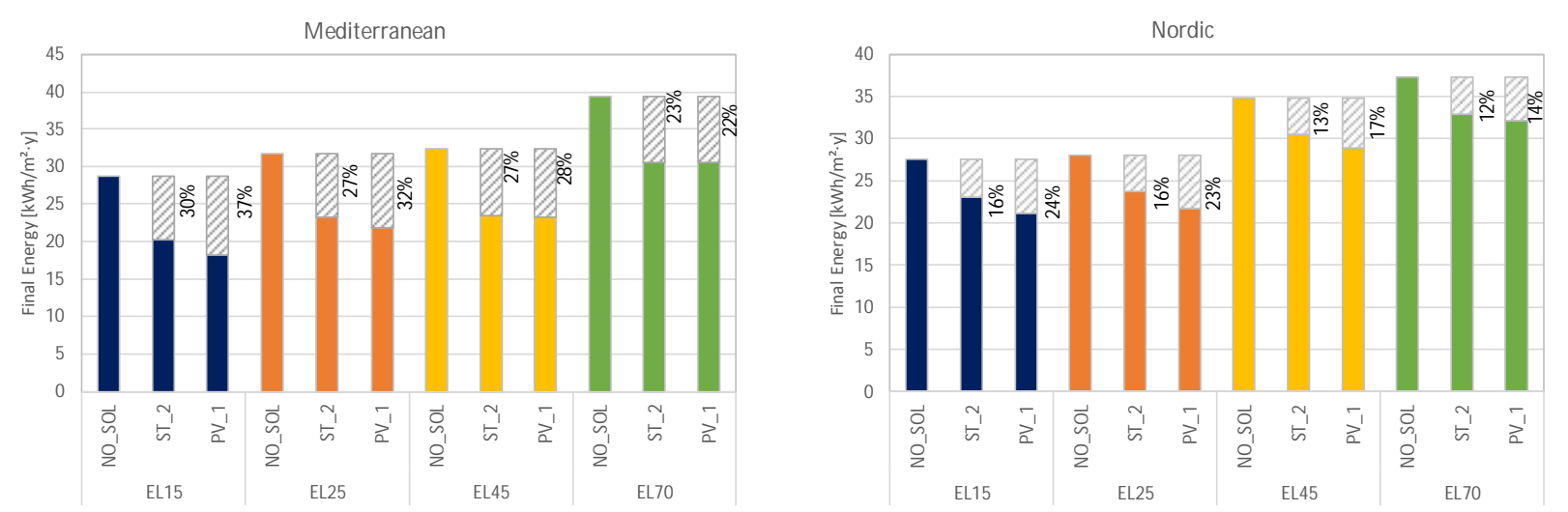

Figure 9 - Comparison of final energy reduction thanks to the adoption of solar thermal or PV system. Case of the Mediterranean climate (left) and Nordic climate (right). 


\section{Simulation results for a Multi Family House reference building from the iNSPiRe project}

As in section 3, this chapter reports on a selection of the cases simulated within the project FP7 iNSPiRe. The whole set of simulations can be found in the reports and database at the link: http://inspirefp7.eu/targetbuilding-simulation-data/. The entire set of boundary conditions and description of simulation models has been reported in deliverables B1, B3 and B4. The reference building here studied is a small multi-family house (sMFH) consisting of 10 apartments distributed on 5 floors having $50 \mathrm{~m}^{2}$ of heated area. As for the SFHs presented in the previous paragraph, simulations are run for seven locations around Europe and four heating demand energy levels, $15,25,45$ and $70 \mathrm{kWh} / \mathrm{m}^{2} \cdot \mathrm{y}$. The energy plant layout consists of a generation device chosen between an air-to-water heat pump, ground-to-water heat pump, condensing boiler or pellet boiler coupled with radiators or fan coils or radiant ceilings. In addition to this, a solar thermal (ST) system and a photovoltaic (PV) system with different field sizes and slopes are analysed.

For the sake of clarity, in Table 6 the energy use for space heating, space cooling, DHW production and ventilation is reported for two climates only, Mediterranean and Nordic.

Table 6 Used energy for H\&C, DHW and ventilation - sMFH

\begin{tabular}{cccccc}
\hline CLIMATE & $\begin{array}{c}\text { ENERGY } \\
\text { LEVEL }\end{array}$ & SPACE & SPACE & DHW & VENTILATIO \\
& HEATING & COOLING & PRODUCTIO & N \\
& {$\left[k W h / m^{2} y\right]$} & {$\left[k W h / m^{2} y\right]$} & {$\left[k W h / m^{2} y\right]$} & {$\left[k W h / m^{2} y\right]$} & {$\left[k W h / m^{2} y\right]$} \\
Nordic & 15 & $\mathbf{1 6 . 0}$ & $\mathbf{1 4 . 3}$ & 20.9 & 4.0 \\
& 25 & $\mathbf{2 2 . 1}$ & $\mathbf{1 3 . 0}$ & 21.0 & 4.0 \\
& 45 & $\mathbf{4 0 . 6}$ & $\mathbf{1 4 . 0}$ & 21.6 & 0.0 \\
& 70 & $\mathbf{3 6 . 7}$ & $\mathbf{1 5 . 0}$ & 21.6 & 0.0 \\
\hline Mediterranean & 15 & $\mathbf{1 1 . 4}$ & $\mathbf{2 8 . 1}$ & 21.2 & 4.0 \\
& 25 & $\mathbf{2 4 . 4}$ & $\mathbf{3 1 . 6}$ & 21.5 & 4.0 \\
& 45 & $\mathbf{3 3 . 2}$ & $\mathbf{3 2 . 7}$ & 21.8 & 0.0 \\
& 70 & $\mathbf{3 2 . 1}$ & $\mathbf{3 4 . 4}$ & 21.9 & 0.0 \\
\hline
\end{tabular}

As for SFH, some cases do not exactly match with the targeted energy level because of the use of discrete values for the definition of insulation thickness and windows quality.

\subsection{Air Source Heat Pump with Radiant Ceilings}

The following paragraphs report results referred to a system with a centralized air-to-water heat pump that covers the space heating, cooling and DHW loads of a sMFH. The distribution system includes radiant ceilings fed with water at $35^{\circ} \mathrm{C}$.

The contribution of electricity produced by a PV system and thermal energy provided by a ST system is also considered.

\subsubsection{Final Energy and SPF}

Figure 10 shows the Final Energy consumption for the different uses of a MFH. A significant impact on the total final energy consumption in renovated buildings is due to space cooling, especially in the southern climates, while in the northern climate for buildings with high performant envelope, EL15, the contribution of space heating, cooling and mechanical ventilation on the total building consumption is similar. In EL15 and EL25, the consumption due to DHW preparation is the highest energy consumption. 

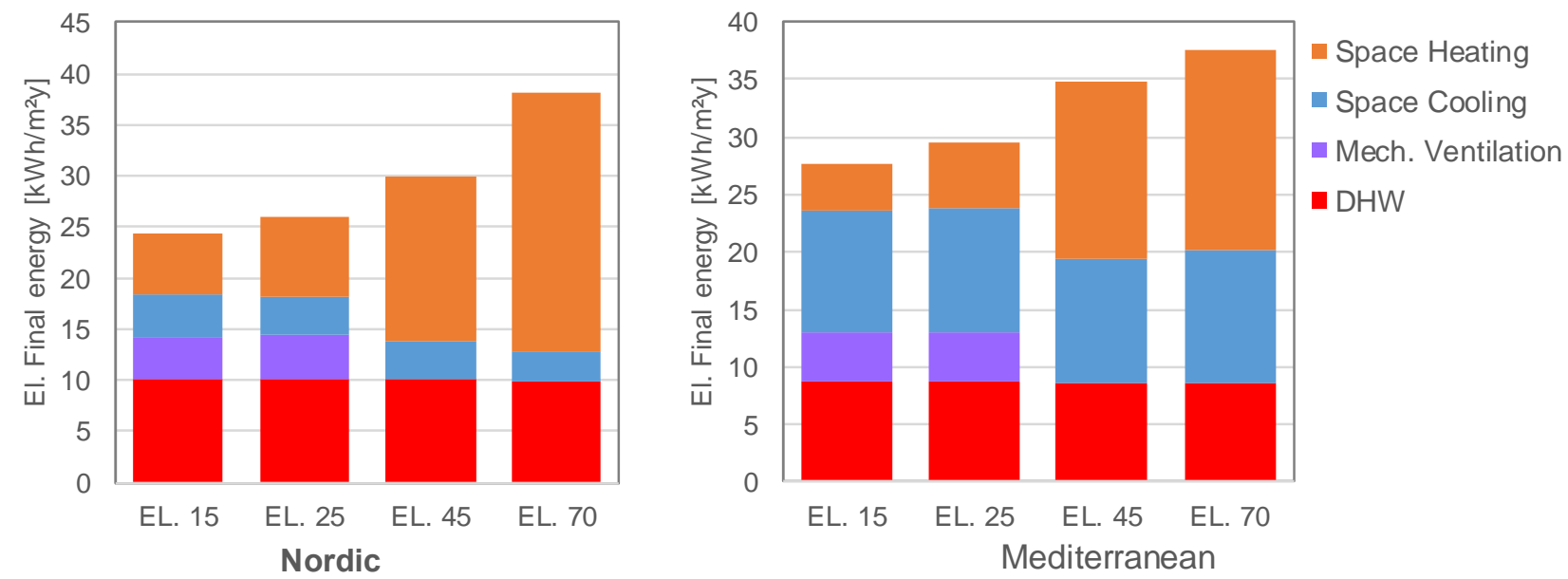

Figure 10 - Final energy distribution without solar systems and a heating water temperature level of $35^{\circ} \mathrm{C}$.

The SPF figures for heating loads vary between 3.1 and 3.6 (the highest in the Mediterranean climate) and between 3.7 and 4 for cooling loads (the highest in the Nordic climate). The SPFs related to the DHW preparation range between 2.2 and 2.6 due to the high thermal losses of the centralized system.

According to this, the overall SPF for heating, cooling, DHW loads and ventilation vary in a range of 2.3 to 3.4 with lower values in the Northern climates and buildings with the highest envelope efficiency standards.

Table 7 - Seasonal performance Factor for DHW, space heating, space cooling and total

\begin{tabular}{|l|l|l|l|l|l|l|l|l|}
\hline & \multicolumn{4}{|l|}{ SPF - Mediterranean } & \multicolumn{2}{l|}{ SPF - Nordic } \\
\hline & DHW & $\begin{array}{l}\text { Space } \\
\text { Heating }\end{array}$ & $\begin{array}{l}\text { Space } \\
\text { Cooling }\end{array}$ & Total & DHW & $\begin{array}{l}\text { Space } \\
\text { Heating }\end{array}$ & $\begin{array}{l}\text { Space } \\
\text { Cooling }\end{array}$ & Total \\
\hline EL.15 & 2.5 & 3.2 & 3.8 & 2.8 & 2.2 & 2.9 & 4.0 & 2.3 \\
\hline EL.25 & 2.5 & 3.3 & 3.8 & 2.8 & 2.2 & 3.0 & 3.9 & 2.3 \\
\hline EL.45 & 2.6 & 3.6 & 3.7 & 3.4 & 2.2 & 3.1 & 3.9 & 2.9 \\
\hline EL.70 & 2.6 & 3.6 & 3.7 & 3.4 & 2.2 & 3.2 & 3.7 & 3.0 \\
\hline
\end{tabular}

\subsubsection{Solar thermal energy utilisation}

The use of solar thermal collectors in MFHs is the same as for the SFHs, that is, for both space heating and DHW preparation. Due to the small size of the storage tank however, the smaller solar system (8 solar collectors, $50 \mathrm{l} / \mathrm{m}^{2}$ ) is only used for DHW preparation.

Slight lower SF values are observed in MFHs with respect to SFH due to the smaller ratio of collectors area over heated area. Despite this, in the Mediterranean case the smallest solar field area can contribute with 20 to $40 \%$ of the total heating production that, referred to the DHW only, results on the $60 \%$ of the total production. In the Northern climate, the contribution of solar collectors lies around $10 \%$ of the total heating production for EL70 buildings up to 35\% in EL15 with the biggest solar field area (see Figure 11). Solar fraction for DHW only, in the Northern climates is around $35 \%$ for the smallest collector field. 

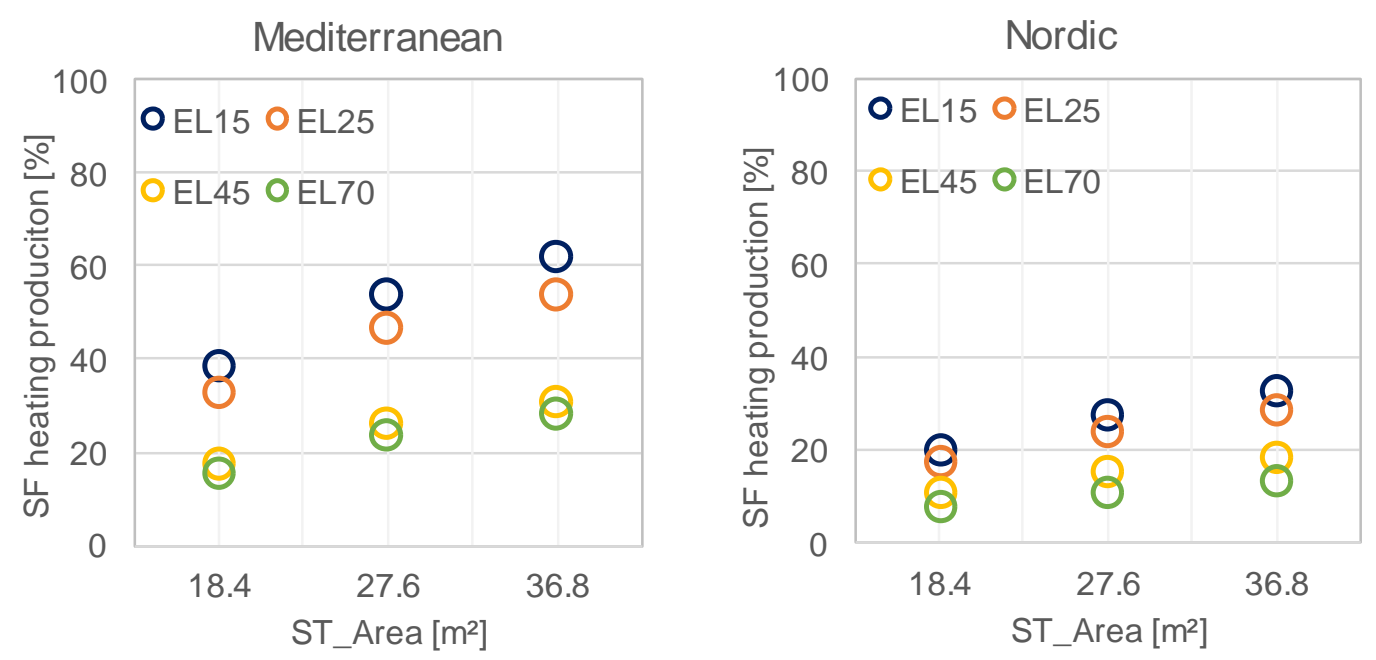

\section{Figure 11 - Solar fraction of heat production (space heating + DHW) for different solar thermal fields areas in the Mediterranean (left) and Nordic (right) climates for a sMFH}

In MFHs, stagnation hours are strongly reduced due to the smaller ratio of solar collectors over heated area. Despite that, the biggest solar field size $\left(37 \mathrm{~m}^{2}\right)$ in the Mediterranean climate with an inclination of $30^{\circ}$ causes more than 600 hours of stagnation. Changing the position, from $30^{\circ}$ to $90^{\circ}$, stagnation phenomena disappears with a reduction of SF of 5-10\% (see Figure 12).

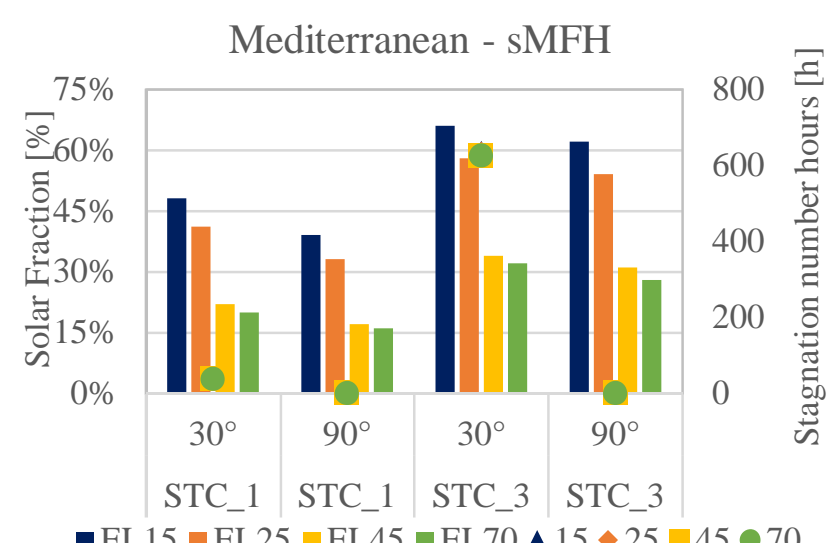

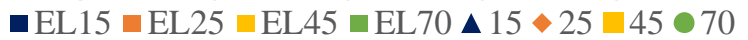

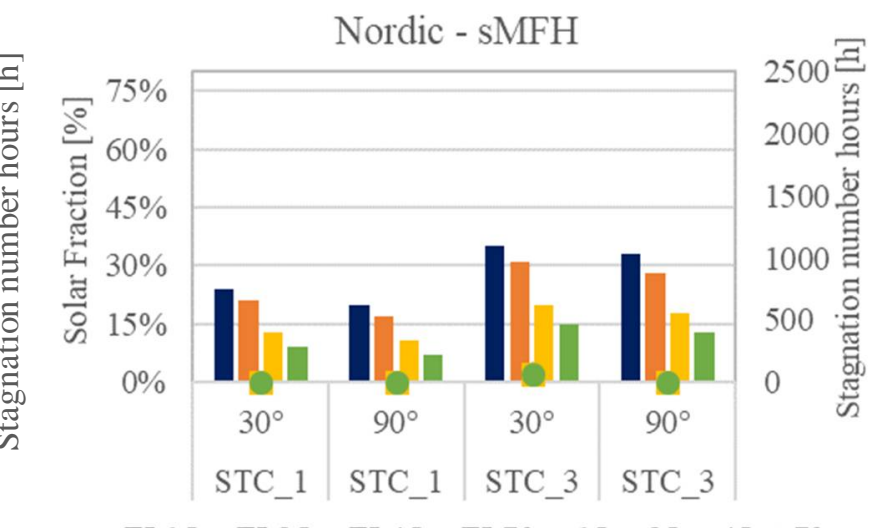

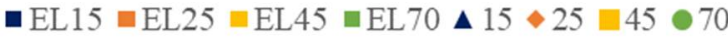

\section{Figure 12 - Solar fraction and stagnation hours for two solar field areas and panels slope}

Looking at the total final energy consumption for heating production, solar thermal collectors help in reducing the total electricity consumption used by the HVAC system. In EL15 with the biggest ST field area, electricity is reduced by one third in the Northern climate up to $60 \%$ in the Mediterranean one. For the EL70, the energy reduction amounts to $14 \%$ and $31 \%$ respectively in the two climates and for the biggest ST area (see Figure $13)$.

Interesting to note that doubling the solar field area, savings are not double and increasing the number of collectors the electricity consumption decrease tending to a minimum value. This last point is due to the fact that, for the presented case, control strategies that maximize the use of solar energy are not implemented. 

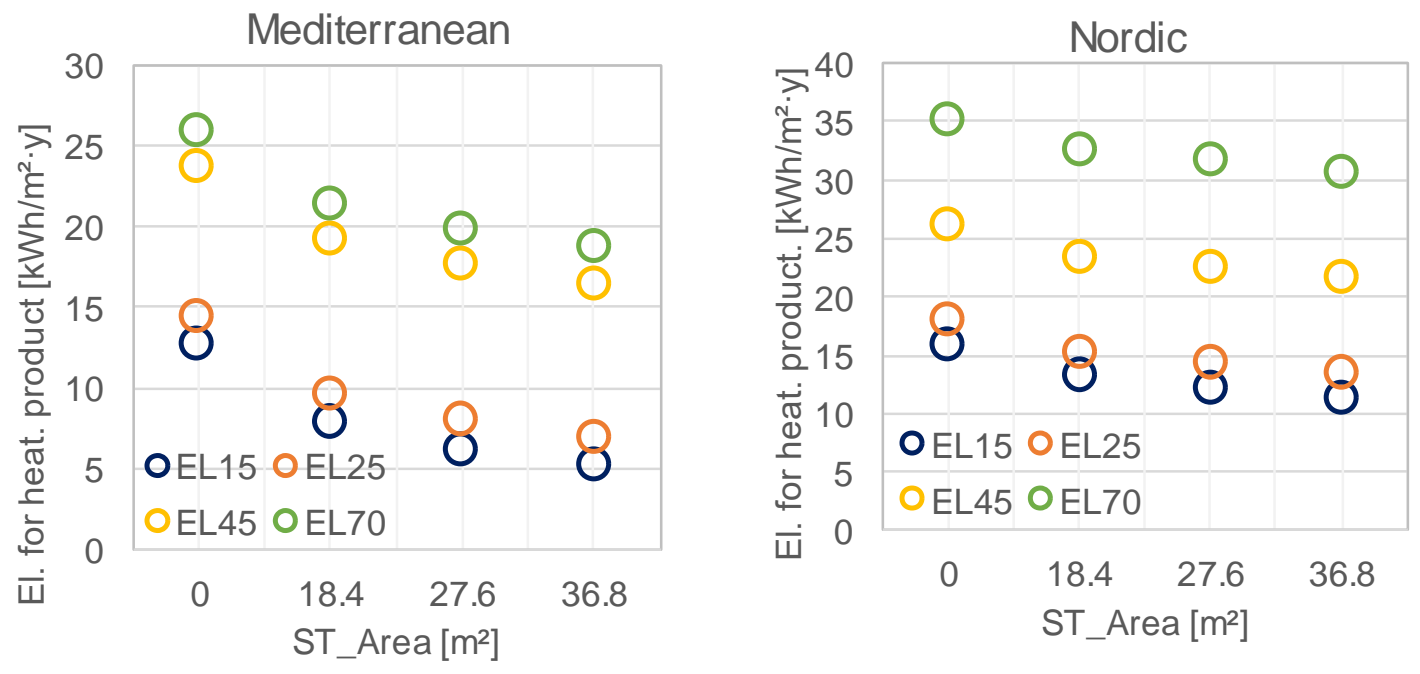

Figure 13 - Final electric energy savings without and with different solar thermal fields, in two locations

\subsubsection{Solar PV energy utilisation}

Figure 14 shows the utilisation of the PV electricity to drive the HVAC system, lighting and appliances, and the surplus production fed into the grid. Calculations are made considering the hourly production/consumption without any battery.

By HVAC system, installing $3 \mathrm{kWp}\left(24 \mathrm{~m}^{2} \mathrm{PV}\right.$ field area both $30^{\circ}$ and $90^{\circ}$ slope $)$ almost the whole produced energy is self-consumed by the HVAC system, lighting and appliances. In case of a $5 \mathrm{kWp}$ installation, the PV production increases by $20-30 \%$ (depending on climate and heating standard), that means in absolute terms around $600-1600 \mathrm{kWh} / \mathrm{y}$.

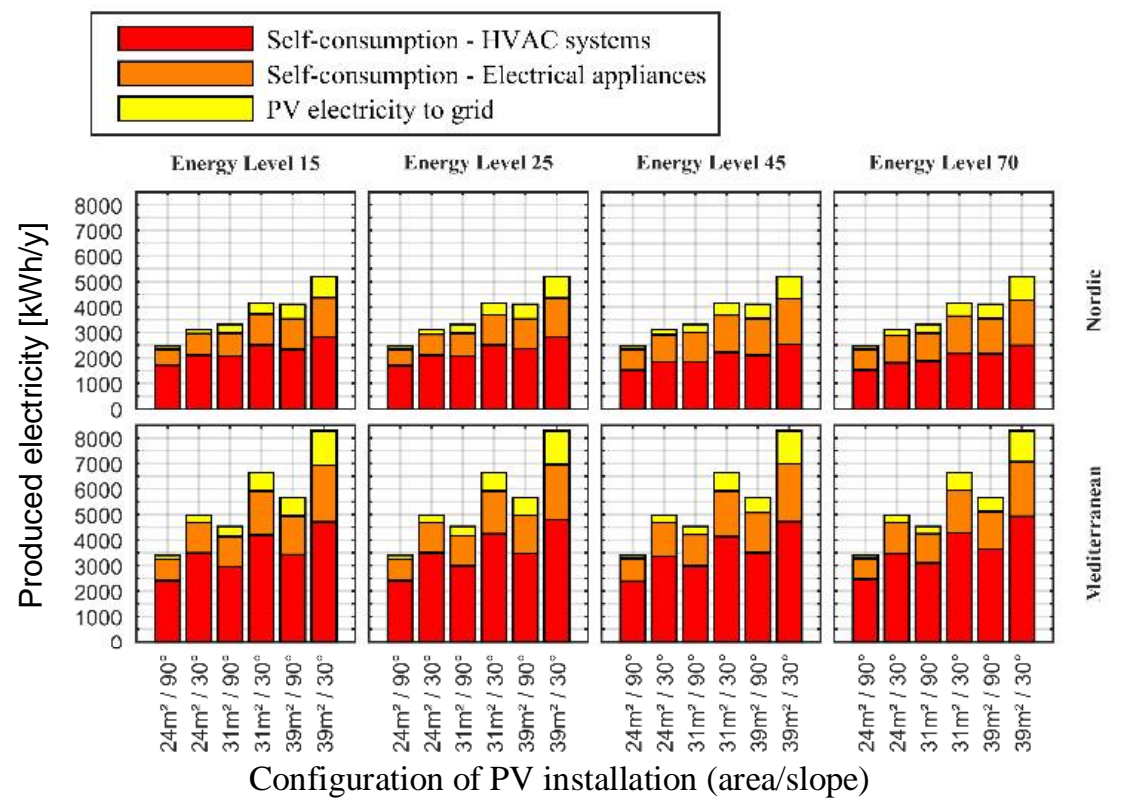

Figure 14 - Photovoltaic electricity production and use

Looking at the cooling load only, with the smallest PV field the energy consumption is reduced by $30-40 \%$ (EL70) to 40-48\% (EL15) in the Mediterranean and Nordic climates. The impact is lower than in SFHs due to 
the lower ratio between installed PV area and living area. Bigger installed PV area results with bigger savings up to 57\% in EL15 Nordic climate and 52\% in EL15 Mediterranean climate (see Table 8).

Table 8 - Electricity consumption for cooling loads at different PV field areas

\begin{tabular}{|l|l|l|l|l|l|l|l|l|}
\hline PV field & \multicolumn{4}{l}{ Mediterranean $\left[\mathrm{kWh} / \mathrm{m}^{2}\right]$} & \multicolumn{2}{l|}{ Nordic $\left[\mathrm{kWh} / \mathrm{m}^{2}\right]$} \\
\hline$\left[\mathrm{m}^{2}\right]$ & EL15 & EL25 & EL45 & EL70 & EL15 & EL25 & EL45 & EL70 \\
\hline 0.0 & 10.5 & 10.7 & 10.8 & 11.6 & 4.1 & 3.8 & 3.7 & 2.9 \\
\hline 23.6 & 6.2 & 6.4 & 7.2 & 8.0 & 2.1 & 2.0 & 2.0 & 1.7 \\
\hline 31.5 & 5.5 & 5.6 & 6.4 & 7.1 & 1.9 & 1.7 & 1.7 & 1.5 \\
\hline 39.4 & 5.1 & 5.1 & 5.8 & 6.5 & 1.8 & 1.6 & 1.5 & 1.3 \\
\hline
\end{tabular}

In MFHs with a centralized system, the coupling of a heat pump with PV results a successful solution, although without any optimized control and a small solar field. In fact even with a 3 or $4 \mathrm{~kW}$ of PV field, the HVAC system self-consumption is maximized reducing the quantity of energy fed into the grid and savings on the total final energy can amount to $35-22 \%$ for the Mediterranean climate and to $23-10 \%$ for the Northern climate (see Figure 15).
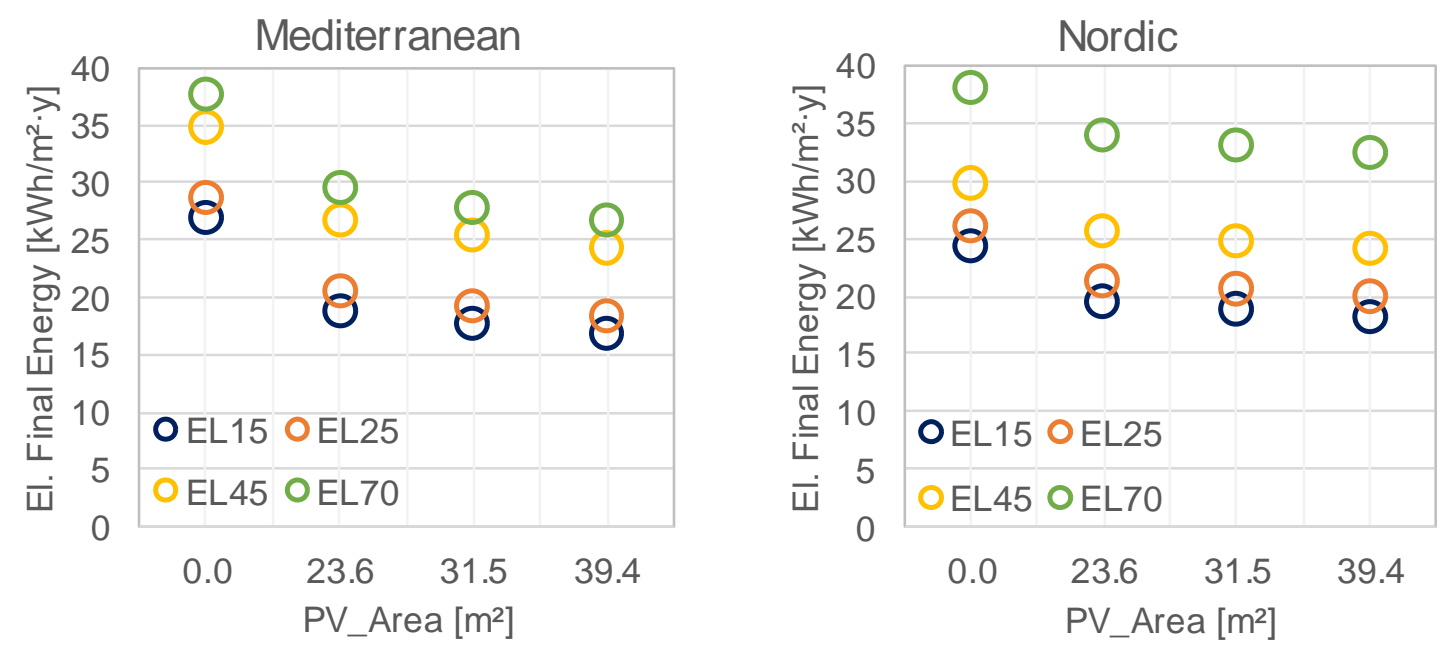

Figure 15 - Final electric energy savings without and with different PV field areas, in two locations

\subsubsection{Final Energy and Primary Energy considerations}

In Figure 16 can be seen as the total primary energy for a EL70 building in both climates exceeds the value of $100 \mathrm{kWh} / \mathrm{m}^{2} \mathrm{y}$. The contribution of solar technologies can decrease this value with larger impact on the Mediterranean climate. In this location, between the two analysed solar technologies, the PV system is the one that obtains a bigger reduction of PE with respect to a solar thermal system due to the not negligible cooling load. The use of both systems can cut one third of the total PE.

In more performant buildings, the EL15s, the contribution of a PV or ST system acts similarly on the total PE consumption although with a higher percentage on the total with respect to a EL70.

In Northern climates, the reduction of PE consumption due to the use of solar technologies is lower than in southern climates, with a percentage of around $15 \%$. The use of PV or ST is quite comparable. 


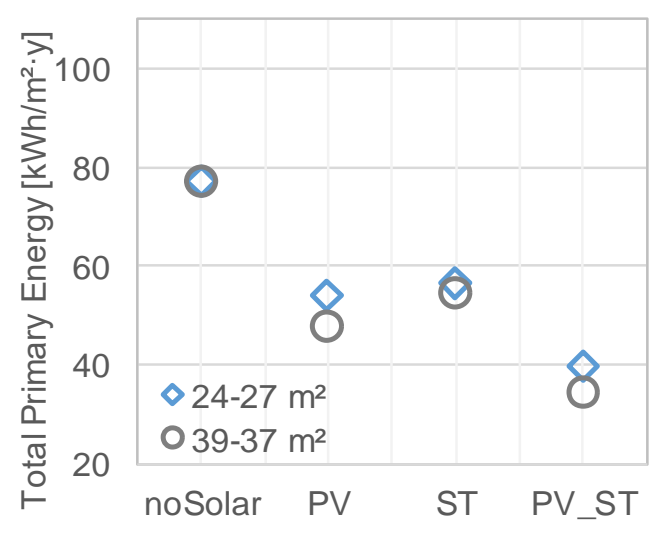

Mediterranean - EL15

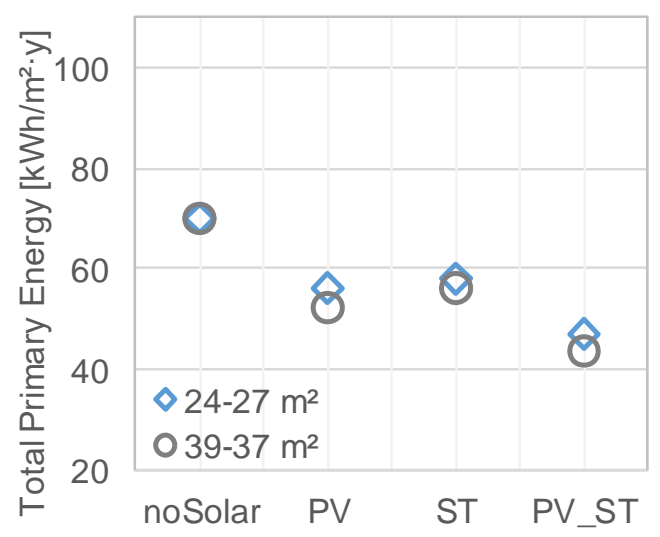

Nordic - EL15
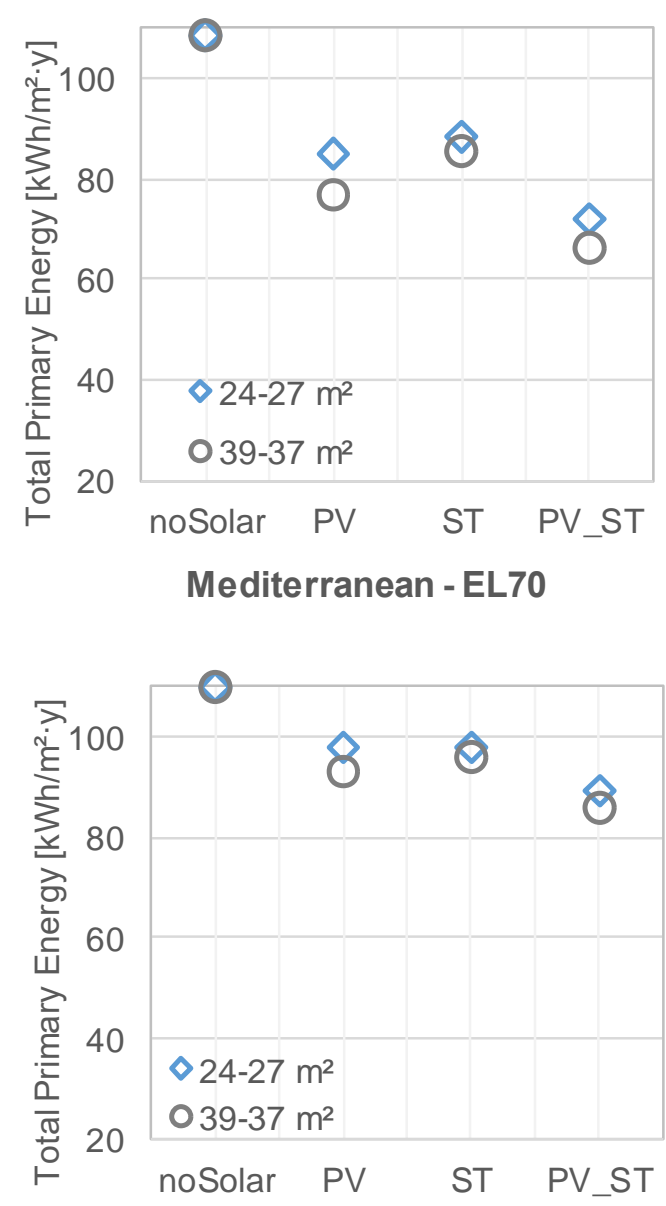

Nordic - EL70

Figure 16 - Comparison of Total Primary Energy consumption for all the building uses without any solar energy system (noSolar), with a PV system (PV), with a solar thermal system (ST) and with both technologies (PV_ST). The considered areas are for PV $23.6 \mathrm{~m}^{2}$ and $39.4 \mathrm{~m}^{2}$ while for ST $27.6 \mathrm{~m}^{2}$ and $36.8 \mathrm{~m}^{2}$

Figure 17 summarizes the SPF for all the uses for the above-described cases. The use of one of the two solar technologies can increase the SPF of around 1 point in the Mediterranean climate and 0.5-0.8 in the Northern one. In the warmer climate the contribution of PV, bigger solar field size, gives higher SPF values, while for the other cases, the field size and technology give similar results. The combination of the two technologies can even significantly increase the performance in the Mediterranean climate, EL15, while slighter improvements can be observed in the other cases.

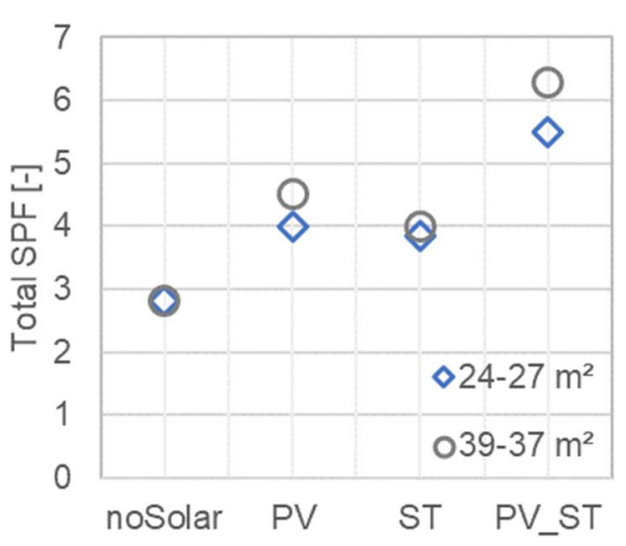

Mediterranean - EL15

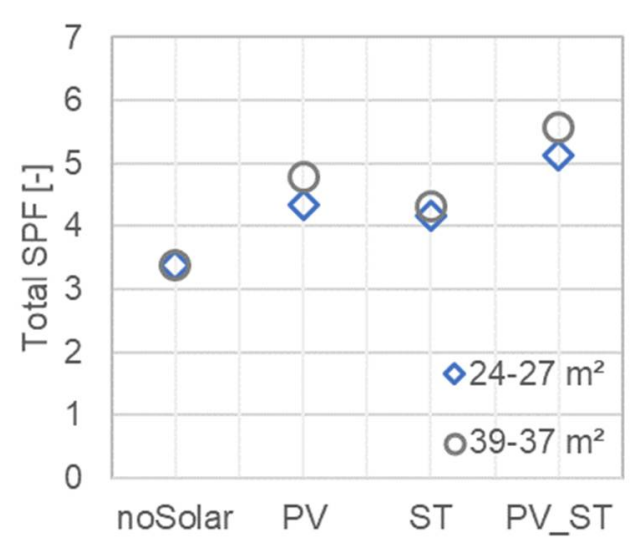

Mediterranean - EL70 


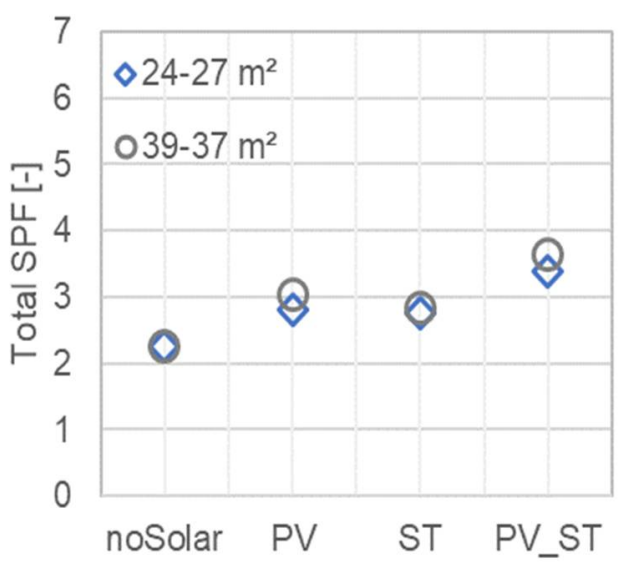

Nordic - EL15

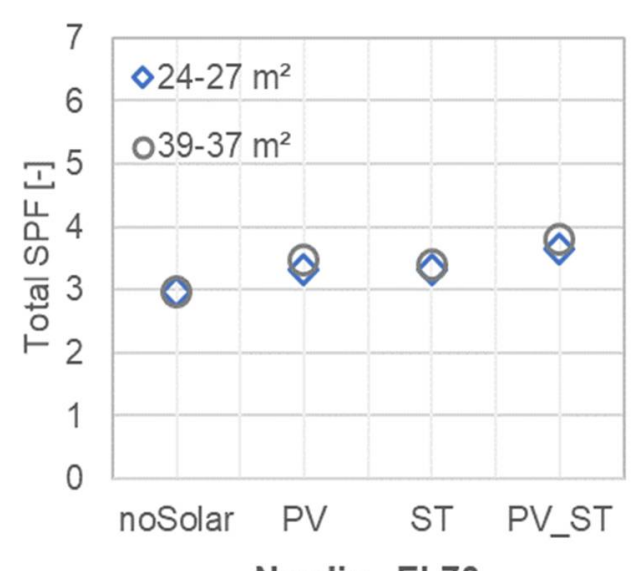

Nordic - EL70

\section{Figure 17 - Comparison of Total SPF for all the building uses without any solar energy system (noSolar), with a PV system (PV), with a solar thermal system (ST) and with both technologies (PV_ST) for two heating demand energy levels of sMFH located in the Mediterranean (above) and Nordic (below) climate}

Table 9 shows the primary energy ratio obtained for two building energy levels, EL15 and EL70, in the two climates. The reported results refer to the already presented different combinations of ST and PV and different solar fields areas.

Table 9 - Primary Energy Ratio for the EL15 and EL70 in the two climates for different combinations and solar fields of ST and PV

\begin{tabular}{|c|c|c|c|c|c|c|c|c|c|c|c|c|c|c|c|c|}
\hline \multirow{3}{*}{\begin{tabular}{|l|} 
PV- \\
ST \\
{$\left[\mathrm{m}^{2}\right]$}
\end{tabular}} & \multicolumn{8}{|c|}{ Mediterranean [-] } & \multicolumn{8}{|c|}{ Nordic [-] } \\
\hline & \multicolumn{4}{|c|}{ EL15 } & \multicolumn{4}{|c|}{ EL70 } & \multicolumn{4}{|c|}{ EL15 } & \multicolumn{4}{|c|}{ EL70 } \\
\hline & $\begin{array}{l}\tilde{\Xi} \\
\dot{0} \\
\tilde{O} \\
\varrho\end{array}$ & 宝 & 年 & $\begin{array}{l}\text { 点 } \\
\text { 定 }\end{array}$ & $\begin{array}{l}\text { जี } \\
0 \\
0 \\
0\end{array}$ & z & 告 & $\begin{array}{l}\text { Es } \\
\text { 己 } \\
2\end{array}$ & 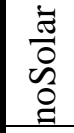 & a & v & $\begin{array}{l}\text { va } \\
\text { 定 }\end{array}$ & 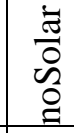 & a & Es & $\begin{array}{l}\text { E) } \\
z_{1}\end{array}$ \\
\hline 0.0 & 1.0 & 1.0 & 1.0 & 1.0 & 1.2 & 1.2 & 1.2 & 1.2 & 0.8 & 0.8 & 0.8 & 0.8 & 1.0 & 1.0 & 1.0 & 1.0 \\
\hline $8-9$ & 1.0 & 1.4 & 1.3 & 1.9 & 1.2 & 1.5 & 1.4 & 1.8 & 0.8 & 1.0 & 1.0 & 1.2 & 1.0 & 1.2 & 1.2 & 1.3 \\
\hline $14-16$ & 1.0 & 1.5 & 1.4 & 2.2 & 1.2 & 1.6 & 1.5 & 1.9 & 0.8 & 1.0 & 1.0 & 1.3 & 1.0 & 1.2 & 1.2 & 1.3 \\
\hline
\end{tabular}

Figure 18 shows the total final energy consumption for the two analysed climates and the four buildings ELs. For each of these cases, the reduction due to the adoption of the PV technology ( $23.6 \mathrm{~m}^{2}$ of solar field) and of the ST panels (27.6 $\mathrm{m}^{2}$ of solar field) is presented.

The behavior of the two technologies is comparable for all the cases and climates. A ST system gives a bigger contribution on reducing the heating demands, especially the DHW load. This can be especially observed in those cases where the cooling load has a minor effect. In line with this, installing a PV or ST system in the Northern climate has very similar impact on the final energy consumption reduction.

In southern climates, the use of PV or ST reduces the total final energy of comparable quantities with a major impact of 3\% of the PV system. In EL15, despite the cooling load represents the main consumption (see Figure $10)$, a ST system decrease the FE consumption of $24 \%$ against $30 \%$ of a PV system. 

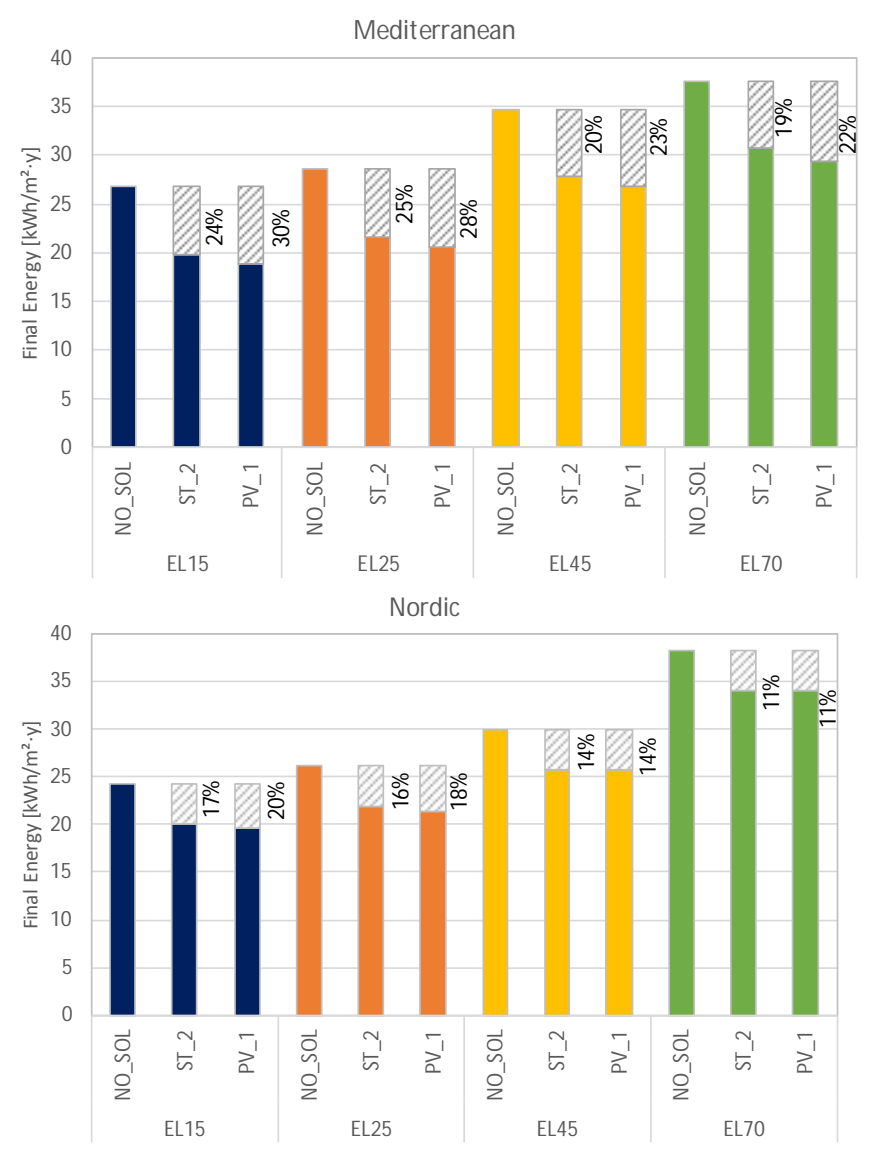

Figure 18 - Comparison of final energy reduction thanks to the adoption of solar thermal or PV system. Case of the Mediterranean climate (left) and Nordic climate (right). 


\section{Simulations results for a Wooden Single-Family House (WRB)}

The present chapter reports on the energy performance of a solar-driven system installed in a building located in nine different locations through Europe. The studied building is a single-family house having bearing structure in XLAM wood panels and thermal insulation in wood fibre and mineral wood. The building is developed in a unique storey for a total heated area of $132 \mathrm{~m}^{2}$.

The building energy plant consists of a solar thermal cooling system, composed of a solar section with evacuated tube collectors and a hot water storage with $1 \mathrm{~m}^{3}$ volume. Cooling is generated by means of an adsorption chiller with rated power of $10 \mathrm{~kW}$, using a gas boiler as back-up when not enough heat from solar collectors is available. Space heating is supplied by means of direct connection of the heating distribution system to the hot water storage; this is maintained at a certain temperature by the solar collectors or the backup gas boiler when the temperature level at the outlet of solar collectors is not enough.

Cooling loads are used as input for the sizing of the solar thermal system. Figure 19 and Figure 20 show the overall heating/cooling demand and peak load for the various cities.

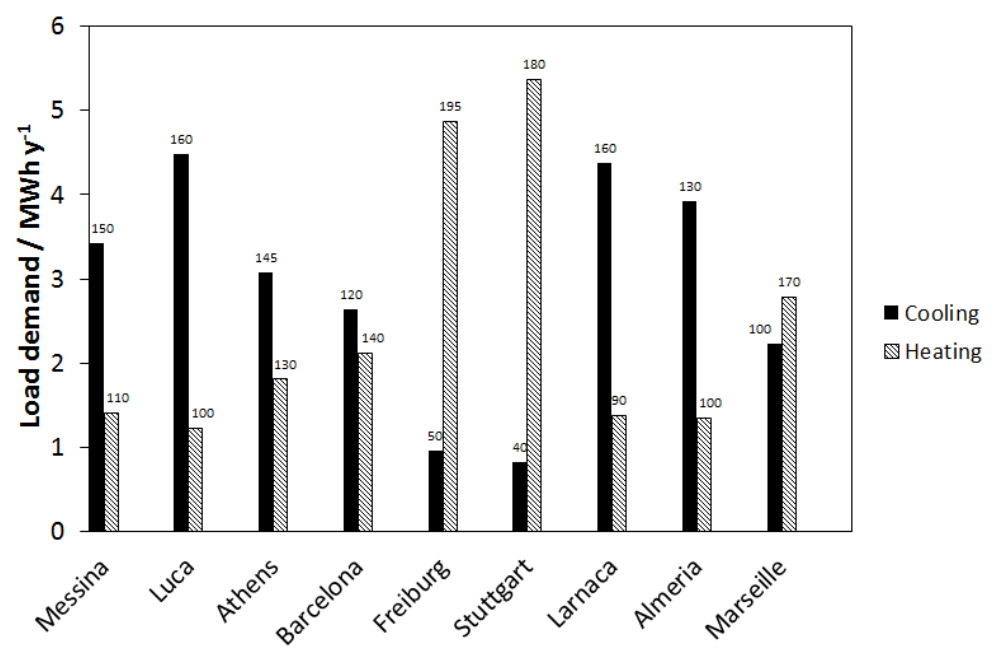

Figure 19: Total annual heating and cooling demand for the reference building in the examined cities. The numbers over the bars indicate the duration (in days) of the heating or cooling season

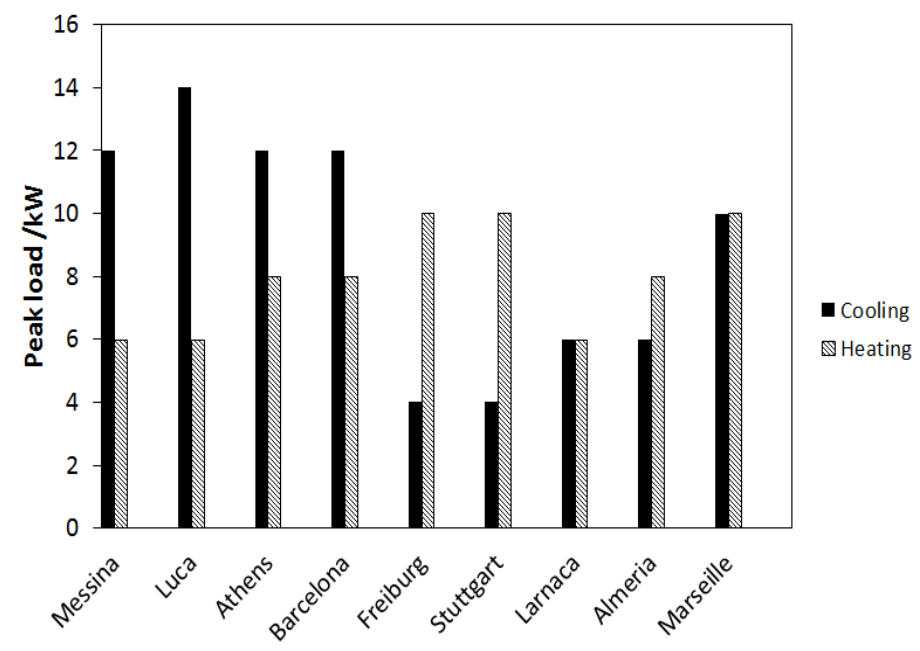


Based on the results, different extensions of solar collector fields were considered, ranging from $24 \mathrm{~m}^{2}$ to 40 $\mathrm{m}^{2}$ (see Table 10). A deeper analysis in both summer and winter mode was operated for the cases that presented a solar fraction for cooling $\left(\mathrm{SF}_{\mathrm{SC}}\right)$ equal to 0.85 . Systems with $\mathrm{SF}_{\mathrm{SC}}$ higher than this value could be considered as totally renewable energy driven and may result expensive. On the contrary, systems with $\mathrm{SF}_{\mathrm{SC}}$ lower than 0.85 relies on primary sources quite heavily.

In the following, seasonal performance factor (SPF), primary energy ratio (PER), solar fraction (SF) and final energy (FE) for the different cases are reported. The definition of these indicators is presented in chapter 2. Regarding the latter parameter, final energy refers to electric consumption $\left(\mathrm{FE}_{\mathrm{el}}\right)$ for all the auxiliaries and gas consumption ( $\left.\mathrm{FE}_{\mathrm{gas}}\right)$ for the back-up unit (during both winter and summer operation).

\subsection{Final Energy and Seasonal Performance Factor}

Within the analysed cases, $\mathrm{FE}_{\mathrm{el}}$ ranges from $2.7 \mathrm{kWh} / \mathrm{m}^{2} \mathrm{y}$ to $7 \mathrm{kWh} / \mathrm{m}^{2} \mathrm{y}$. In particular, $\mathrm{FE}_{\mathrm{el}}$ is higher in continental cities. The main factor influencing this value is the low cooling demand together with the heavy integration by the back-up unit needed during winter: the boiler circuit works with a constant speed hydraulic pump which influences the electric consumption. The lowest values of FE are obtained in Southern dry climate, indicating that the efficiency of the system is maximum under these conditions.

Gas consumption used during summer for integration of the renewable heat for solar collectors to drive the adsorption chiller and during winter for space heating purposes ranges between $12 \mathrm{kWh} / \mathrm{m}^{2} \mathrm{y}$ to $30 \mathrm{kWh} / \mathrm{m}^{2} \mathrm{y}$. Again, the highest values are obtained for the continental climate, due to the integration by means of traditional generation units needed during winter. The results of the overall final energy consumption (gas + electricity) of the Southern continental climate and the Southern dry climates are similar: in this case, the higher gas consumption during winter in Marseille for space heating purposes is compensated by the higher COP of the adsorption chiller during summer that leads to a lower gas consumption during this season. The electricity consumption is needed to drive the auxiliaries of the system, both during summer and winter.

Regarding seasonal performance, the $\mathrm{SPF}_{\mathrm{SH}}$ referred to electric consumption is always higher than 10 in all the cases, with the exceptions of Freiburg and Stuttgart (continental climate), where a significant gas boiler utilisation during winter operation is needed. The highest values are reached in Malta and Messina, corresponding to 14 .

The $\mathrm{SPF}_{\mathrm{SC}}$ ranges between 11 and 13 for Southern Dry and Mediterranean climates. For the Southern Continental climate, represented by the city of Marseille, it is around 10, while it is lower than 7 for the Continental climate. In this case, the reduced number of operation hours of the system during summer, together with the lower requested power, make the consumption of auxiliaries needed to drive the adsorption system more relevant. In turn, this negatively affects the performance of the system.

Accounting for the yearly behaviour in space heating and space cooling mode, the $\mathrm{SPF}_{\text {tot }}$ for electricity ranges between 6 and 13 for the various climates. The parameter takes into account the heating and cooling demands, whereas DHW was not investigated. The highest value is obtained in Malta, even though similar performances are obtained by the system under the other Southern dry and Mediterranean climates. The lowest values are again obtained in the continental regions (see Figure 21).

Figure 22 shows the heating and cooling demands, and the consumed energy of electricity and gas for the two uses. As already anticipated, the results show that the energy needed from the gas boiler for the operation of the chiller is higher in the Southern cities during summer and, as expected, even an order of magnitude higher in Freiburg and Stuttgart during winter. 


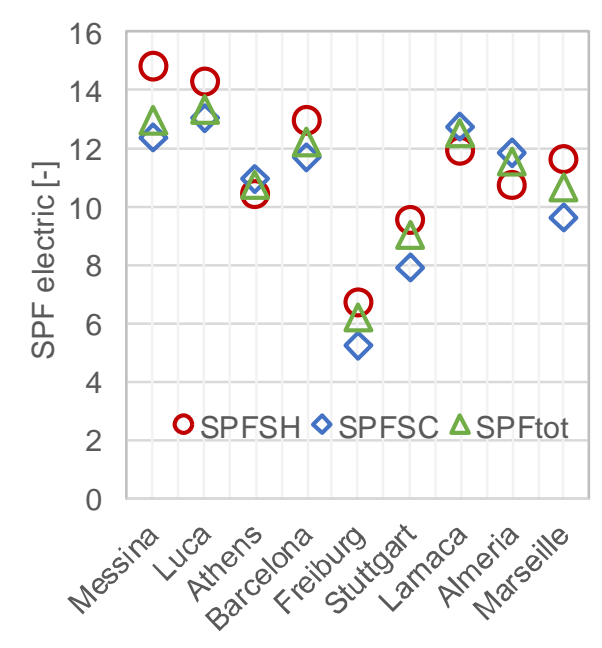

Figure 21 - SPF for the various cities investigated
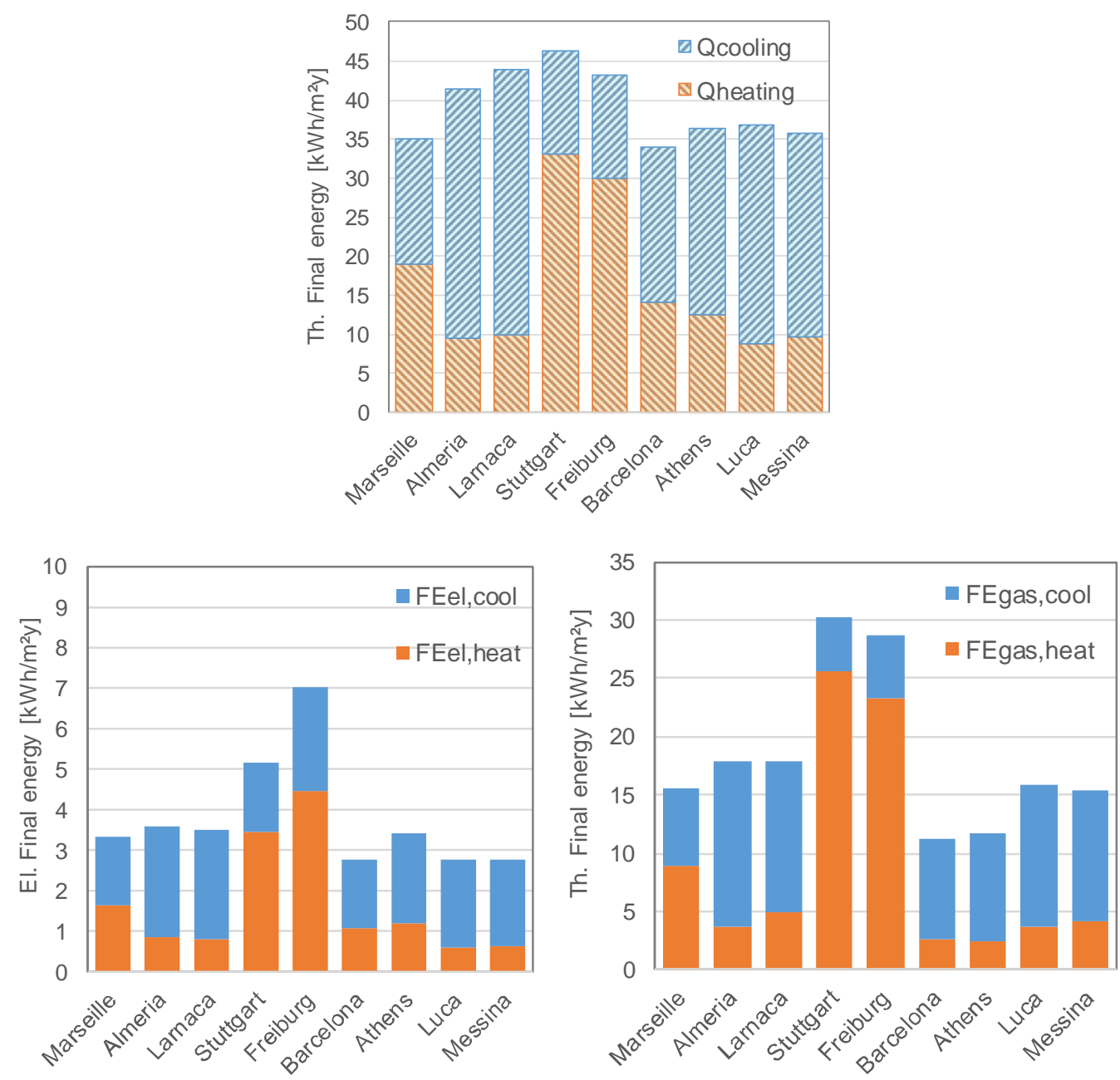

Figure 22 - Heating and cooling demands (above), electric consumption for space heating and cooling (below, left) and thermal consumption (below, right) 


\subsection{Primary Energy and Primary Energy Ratio}

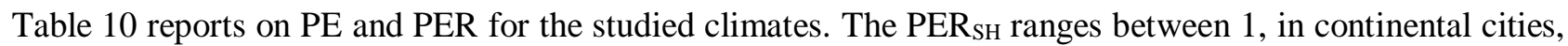
and 3.4 and 3.8 in Barcelona and Athens. This underlines the better working conditions of this specific system in southern climates. Due to the choice of comparing systems with similar $\mathrm{SF}_{\mathrm{SC}}$, the PER $\mathrm{PR}_{\mathrm{SC}}$ for space cooling results to be around 2 for all the cities, with the exception of the northern climates.

The different values of $\mathrm{PER}_{\mathrm{SH}}$ and $\mathrm{PER}_{\mathrm{SC}}$ highlight the difficulty in properly sizing a solar driven system in warmer climates: a sizing based on summer conditions leads to an oversizing of the solar thermal field during winter conditions. Optimal conditions for the two working conditions need to be therefore carefully studied.

Table 10 - Primary Energy Ratio (PER) for the studied cases

\begin{tabular}{|c|c|c|c|c|c|c|c|c|c|}
\hline \multirow[t]{2}{*}{ City } & $\begin{array}{l}\text { Cooling } \\
\text { demand }\end{array}$ & $\begin{array}{l}\text { Heating } \\
\text { demand }\end{array}$ & $\begin{array}{l}\text { Numb } \\
\text { Collect }\end{array}$ & $\mathrm{PER}_{\mathrm{SH}}$ & $\mathrm{PER}_{\mathrm{SC}}$ & $\mathrm{PER}_{\text {tot }}$ & $\mathrm{PE}_{\mathrm{SH}}$ & $\mathrm{PE}_{\mathrm{SC}}$ & $\mathrm{PE}_{\text {tot }}$ \\
\hline & $\mathrm{MWh} / \mathrm{y}$ & MWh/y & - & - & - & - & $\mathrm{kWh} / \mathrm{m}^{2}$ & $\begin{array}{l}\mathrm{kWh} / \mathrm{m} \\
2\end{array}$ & $\mathrm{kWh} / \mathrm{m}^{2}$ \\
\hline Messina & 3.4 & 1.4 & 8 & 2.1 & 2 & 2 & 5.1 & 13.1 & 18.5 \\
\hline Luca & 4.5 & 1.2 & 8 & 2.1 & 2 & 2 & 4.4 & 17.3 & 21.9 \\
\hline Athens & 3.1 & 1.8 & 8 & 3.5 & 2.1 & 2.4 & 4.0 & 11.4 & 15.7 \\
\hline Barcelona & 2.6 & 2.1 & 8 & 3.8 & 1.9 & 2.4 & 4.3 & 10.5 & 15.1 \\
\hline Freiburg & 1 & 4.9 & 6 & 1.1 & 1.6 & 1.2 & 34.3 & 4.8 & 37.8 \\
\hline Stuttgart & 0.8 & 5.4 & 6 & 1.1 & 2.1 & 1.3 & 37.8 & 2.9 & 36.7 \\
\hline Larnaca & 4.4 & 1.4 & 10 & 1.7 & 2.2 & 2.1 & 6.3 & 15.4 & 21.2 \\
\hline Almeria & 3.9 & 1.4 & 8 & 2.1 & 1.9 & 1.9 & 5.1 & 15.8 & 21.5 \\
\hline Marseille & 2.2 & 2.8 & 6 & 1.8 & 2 & 1.9 & 12.0 & 8.5 & 20.2 \\
\hline
\end{tabular}

\subsection{Solar Fraction}

Regarding the solar fraction, as already stated, a similar solar fraction for cooling $\mathrm{SF}_{\mathrm{SC}}$ was chosen within the different climates. The different SF therefore lies for space heating: in continental climates, only about $30 \%$ of heating loads can be met through solar fields, whereas in Southern Continental climate about $56 \%$ of needed heat is provided by solar collectors. In the other cases of warmer climates, the $\mathrm{SF}_{\mathrm{SH}}$ is equal or higher than $90 \%$, indicating that the system can run on renewable energy under the vast majority of conditions (see Figure 23). Even though an economic analysis was not performed for the present case, such results indicate that the operation for the entire year is foreseeable and can thus reduce the payback time.

Solar collectors contribute to the coverage of annual loads demand for more than $60 \%$ in all cases. Except the coldest climates where solar fraction for space heating if around $30 \%$, in the other countries, $\mathrm{SF}_{\text {heat }}$ is around 90\%. This demonstrates as solar cooling systems can be exploited along the year if correctly sized. 


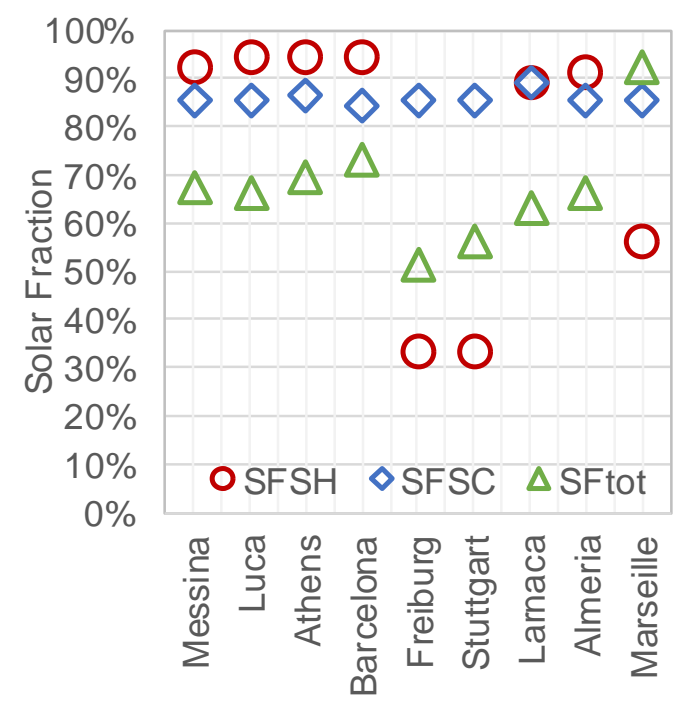

Figure 23 - Solar fraction for the investigated cities. 


\section{Simulations results for a Single-Family House - TheBat building}

TheBat building is based on the SFH defined in Task 44-B. It has a heated surface of $140 \mathrm{~m}^{2}$ distributed in one storey and thermal characteristics are defined in a way to have a yearly heating demand of $45 \mathrm{kWh} / \mathrm{m}^{2} \cdot \mathrm{y}$.

Space heating and DHW production are covered by a geothermal heat pump connected to a PV field. The distribution system consists of thermal activated building system (TABS) while a thermal energy storage (TES) is used for the DHW demand. More details on the layout can be found in deliverable B3.

Different PV sizes, TES sizes and control strategies are tested for maximizing the use of PV energy for running the system. Deliverable B4 describes the adopted strategies, and here are summarized:

- REF

Reference building case with no control strategies (see also 6.1)

- SELF no additional control concepts, PV energy only used if availability and demand coincide

- $\quad$ TES surplus PV energy is stored as heat through overheating of the TES

- BUI: surplus PV energy is stored as heat through overheating of the TABS

- BUI+TES surplus PV energy is stored as heat through overheating of the TES as well as the TABS with a priority on overheating of the TABS

\subsection{Reference building}

The description and the entire set of boundary conditions of the used simulation model has been reported in the deliverables B1, B3 and B4. For comparison purposes, a set of parameters was chosen to represent a reference case building (REF).

As noted, the building matches the one described in deliverable B1. For the varying parameters described in deliverable $\mathrm{B} 3$ the following conditions were chosen:

- TES volume: 5001

- PV-area: $\quad 0 \mathrm{~m}^{2}$ (no PV installed)

For the reference building, none of the additional control strategies for increased PV self-consumption described in deliverable B4 were used.

\subsection{Seasonal performance factors}

To evaluate the effect on performance for the different strategies the following three performance factors were chosen:

- $\quad{ }_{C O P} e_{1, H P}:$ Represents the coefficient of performance as defined in section 1

- $S P F_{n o, P V:}$ Represents the SPF for the heat pump with the total compressor energy demand the reference building uses for space heating and DHW production as useful energy.

- $S P F_{W / P V}$ : Represents the SPF for the heat pump while using the energy from grid for the reference building (SH and DHW) as useful energy.

In Figure 24 the results for these performance factors can be found for the different parameters and control strategies. It can be observed how the different operating conditions (condenser temperature level, start/stop frequency) caused by the different control strategies and TES volumes affect the heat pump efficiency $\left(C O P_{e l}\right.$ ). As can be seen in cases with the only overheating of the TES (TES in Figure 24), the control strategy causes higher operating temperatures which cause a decrease in efficiency of the heat pump. 
When comparing the results for $C O P_{e l}$ with the ones for $S P F_{n o, P V}$, the effect of "unusable" heat produced by the heat pump can be seen. This effect changes based on the different used control strategies and is increased by the coupling of the heat pump with PV-energy availability (as described in deliverable B4). Additional heat produced by the heat pump is lost through higher heat losses of the building and TES. This can be easily observed in cases with overheating of the building (BUI), where higher heat losses further increase the difference between $C O P_{e l}$ and $S P F_{n o, P V}$.

The main target of the model was an increase of PV self-consumption, despite a decrease of the COP. The decreased $C O P_{e l}$ has therefor to be considered in relation to the grid energy consumed, as the PV-energy can be considered "free". This can be observed in the different values of $S P F_{w, P V}$. As can be observed, the $S P F_{w, P V}$ can be increased up to twofold for $20 \mathrm{~m}^{2} \mathrm{PV}$ area (about $2.5 \mathrm{~kW}_{\text {peak }}$ ) and up to fivefold for $40 \mathrm{~m}^{2}$ (about $\left.5 \mathrm{~kW}_{\text {peak }}\right)$.

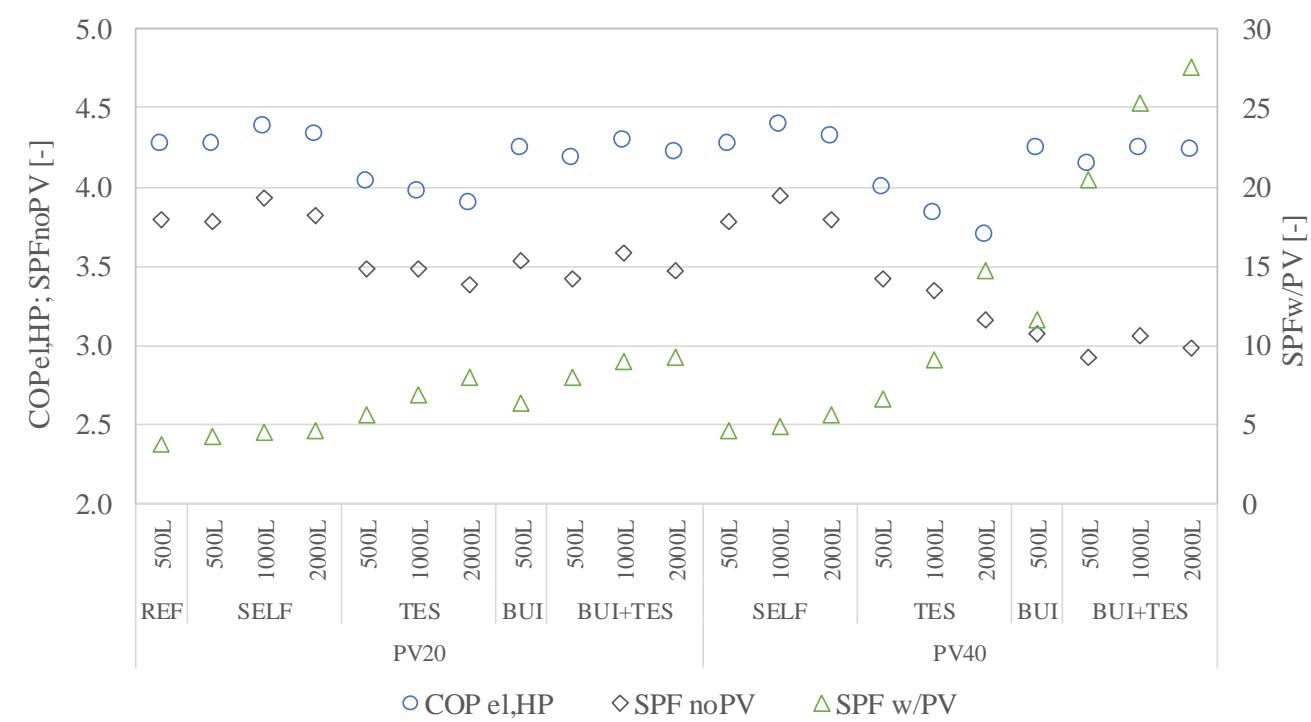

Figure 24 - Seasonal Performance Factor for RES45 in the TheBat model

Table 11 - PE and FE consumption for all the analysed cases

\begin{tabular}{|c|c|c|c|c|c|c|c|c|c|c|c|c|}
\hline & & \multicolumn{11}{|c|}{ PV20 } \\
\hline & & \multirow{2}{*}{$\begin{array}{l}\text { REF } \\
500 \mathrm{~L} \\
\end{array}$} & \multicolumn{3}{|c|}{ SELF } & \multicolumn{3}{|c|}{ TES } & \multirow{2}{*}{$\begin{array}{l}\text { BUI } \\
500 \mathrm{~L} \\
\end{array}$} & \multicolumn{3}{|c|}{ BUI+TES } \\
\hline & & & $500 \mathrm{~L}$ & $1000 \mathrm{~L}$ & $2000 \mathrm{~L}$ & $500 \mathrm{~L}$ & $1000 \mathrm{~L}$ & $2000 \mathrm{~L}$ & & $500 \mathrm{~L}$ & $1000 \mathrm{~L}$ & $2000 \mathrm{~L}$ \\
\hline $\mathrm{PE}$ & {$\left[\mathrm{kWh} / \mathrm{m}^{2} \mathrm{y}\right]$} & 48.5 & 43.7 & 42.1 & 40.8 & 36.3 & 30.7 & 25.7 & 21.6 & 23.7 & 21.4 & 20.6 \\
\hline \multirow[t]{4}{*}{$\mathrm{FE}$} & {$\left[\mathrm{kWh} / \mathrm{m}^{2} \mathrm{y}\right]$} & 16.8 & 15.2 & 14.6 & 14.2 & 12.6 & 10.6 & 8.9 & 7.5 & 8.2 & 7.4 & 7.2 \\
\hline & & & \multicolumn{10}{|c|}{ PV40 } \\
\hline & & & \multicolumn{3}{|c|}{ SELF } & \multicolumn{3}{|c|}{ TES } & BUI & \multicolumn{3}{|c|}{ BUI+TES } \\
\hline & & & $500 \mathrm{~L}$ & $1000 \mathrm{~L}$ & $2000 \mathrm{~L}$ & $500 \mathrm{~L}$ & $1000 \mathrm{~L}$ & $2000 \mathrm{~L}$ & $500 \mathrm{~L}$ & $500 \mathrm{~L}$ & $1000 \mathrm{~L}$ & $2000 \mathrm{~L}$ \\
\hline $\mathrm{PE}$ & {$\left[\mathrm{kWh} / \mathrm{m}^{2} \mathrm{y}\right]$} & & 40.5 & 37.4 & 34.7 & 31.8 & 24.1 & 15.1 & 14.5 & 9.2 & 7.6 & 7.2 \\
\hline $\mathrm{FE}$ & {$\left[\mathrm{kWh} / \mathrm{m}^{2} \mathrm{y}\right]$} & & 14.1 & 13.0 & 12.1 & 11.1 & 8.4 & 5.2 & 5.0 & 3.2 & 2.7 & 2.5 \\
\hline
\end{tabular}

It can also be observed that for cases with $20 \mathrm{~m}^{2}$ of PV, different control strategies cause similar results. The control strategy "overheating of the TES" (TES) with a TES volume of 20001 causes a similar effect to the control strategy "overheating of the TES and the building" (BUI+TES) with a TES volume of 5001 . In cases with $40 \mathrm{~m}^{2}$, it can be observed that the increase of PV self-consumption increases distinctly for cases with a TES volume of 20001 as well as those with overheating of the building. This is largely caused by the limitation of the lower storage volumes, which are already fully utilized for $20 \mathrm{~m}^{2}$. The increased PV area therefore has a limited effect on those control strategies. The larger tank as well as the building can be utilized to store this 
additional energy which leads to way higher self-consumption rates. Table 11 summarizes PE and FE for all the studied cases.

\subsection{Solar fraction and useful heat}

To evaluate the effects of the different system configurations and control strategies outlined in deliverable B1B4, several key figures were used. Those figures are defined as follows:

- SF_SH: Solar Fraction is defined as useful heat provided by the heat pump with PV-electricity divided by total heat provided by the heat pump.

- Heat $t_{\mathrm{HP}, \mathrm{PV}, \text { grid: }}$ heat produced by the heat pump with electricity from the grid;

- Heat ${ }_{\mathrm{HP}, \mathrm{PV}, \mathrm{useful}}$ : useful heat produced by the heat pump with PV electricity;

- Heat ${ }_{\mathrm{HP}, \mathrm{PV}, \mathrm{loss}}$ : heat produced by the heat pump with PV electricity and wasted through thermal losses;

The results for these key figures for the different cases are presented in Figure 25 . For the system with $20 \mathrm{~m}^{2}$ $\mathrm{PV}$ area (about $2.5 \mathrm{~kW}_{\text {peak }}$ ) and the standard TES volume of 500 liter a solar fraction of SF_HP=11\% can be achieved with the SELF control concept resulting in a useful heat production based on PV-electricity (Q_PVHeat_useful_spec) of 1.4 MWh. By increasing the TES volume up to 2,000 liter, a SF_HP=19\% and 2 MWh of useful heat can be achieved.

When changing from the SELF to the TES control strategy, the results of the case with 500 liter TES volume changes significantly, increasing the solar fraction to $29 \%$ and useful heat produced by PV of $3 \mathrm{MWh}$. This control concept doubles the results compared to the SELF control concept. By increasing the TES volume up to 2,000 liter, a solar fraction of SF_HP=51\% and 5.3 MWh of useful heat can be achieved.

Changing to the BUI control concept while keeping the TES volume of 500 liter, a solar fraction of $45 \%$ and useful heat of $4.2 \mathrm{MWh}$ can be achieved, which is a further increase of 50\% compared to the TES control concept. But in this case, it is important to note the potential decrease in living comfort, because the average room temperature is significantly higher due to overheating of the building reaching up to $26^{\circ} \mathrm{C}$. It can also be observed that the produced energy by PV and wasted through thermal losses becomes significant with respect to the previous cases (see also Figure 26).

Using the combined control concept BUI+TES with 500 liter TES volume, a further increase of solar fraction to $48 \%$ and useful heat of $5.2 \mathrm{MWh}$ can be achieved, which is an $80 \%$ increase compared to the TES control concept and still a $22 \%$ increase compared to the BUI concept. When considering these results, again like the BUI concept, it has to be considered that these higher temperatures in the building have a negative effect on the living comfort. In comparison, with the TES concept and 2,000 liter TES volume, an equivalent solar fraction and useful heat can be achieved without any comfort disadvantages. With the BUI+TES concept with 2,000 liter TES volume, the highest solar fraction of 54\% and useful heat of 5.8 MWh can be achieved.

The results when increasing the PV area from $20 \mathrm{~m}^{2}$ to $40 \mathrm{~m}^{2}\left(\sim 2.5 \mathrm{~kW}_{\text {peak }}\right.$ to $\left.\sim 5 \mathrm{~kW}_{\text {peak }}\right)$ are presented on the right side of Figure 25. While solar fractions and useful heat produced with PV electricity are significant higher, the standard SELF concept still only exhibits a solar fraction of SF_HP=18\%, which is only a minor increase compared to $11 \%$ for $20 \mathrm{~m}^{2} \mathrm{PV}$. With the TES concept and 2,000 liter TES volume an already remarkable solar fraction of $72 \%$ can be achieved with PV40, but useful heat is only $7.5 \mathrm{MWh}$ compared to 5.3 MWH with PV20. However, the remarkable potential with PV40 is a solar fraction of $70 \%$ using the TES+BUI concept with the standard TES volume of 500 liter, which is almost what can be reached with 2,000 liter TES volume (SF_HP=72\%). The combination of BUI+TES presents a large part of thermal losses that can be avoided or, at least, reduced with the TES control strategy. 


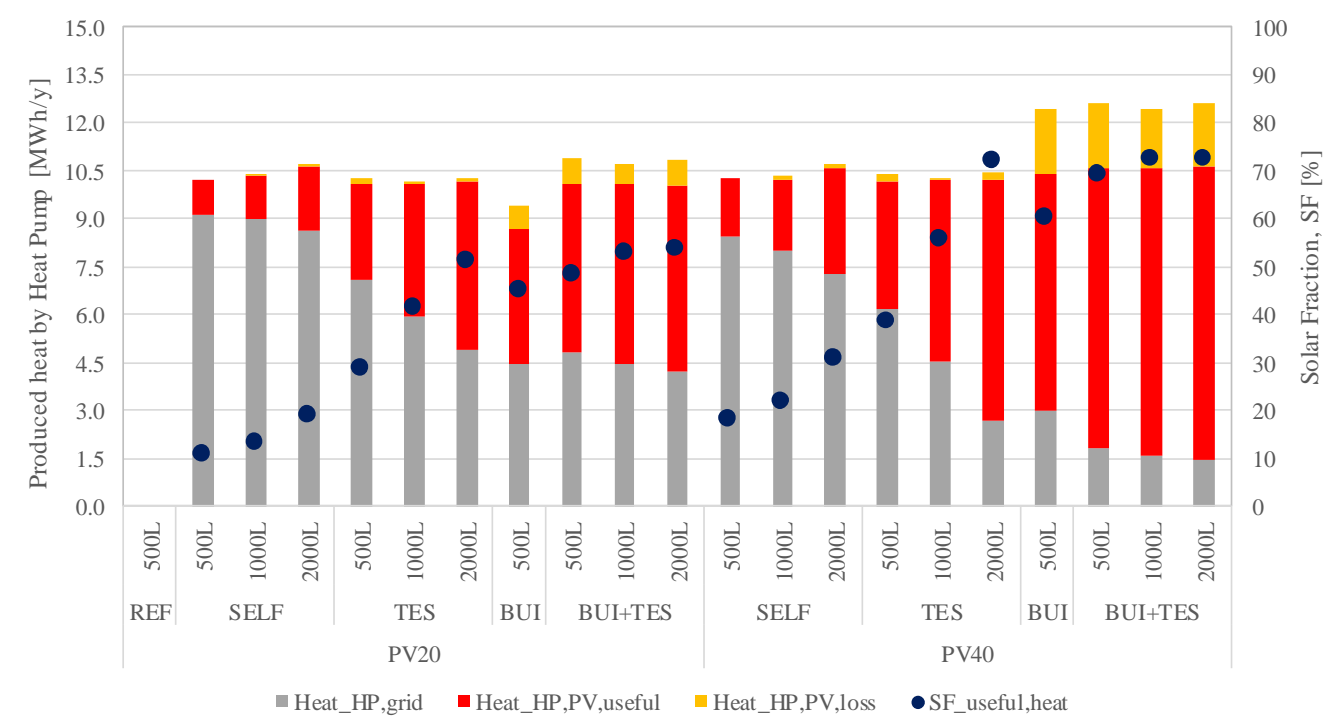

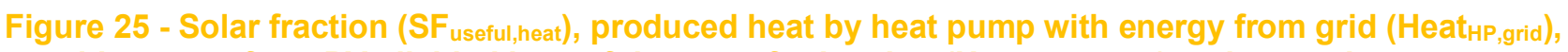
with energy from PV, divided in useful energy for heating (Heat $\left.{ }_{H P, P V, u s e f u l}\right)$ and wasted energy as thermal losses (Heat ${ }_{H P, P V, l o s s}$ ) depending on control algorithm and PV area.

\subsection{Energy balance and room temperature}

To display the effects of the different system configurations and control concepts, their results are displayed in Figure 26. For overview purposes, only the cases with $20 \mathrm{~m}^{2}$ of PV are displayed here.

As mentioned, the main goal is to maximize the direct PV electricity (PV to HP) consumption by the heat pump and therefor to minimize the grid electricity consumption (Grid to HP). The concept used to reach this goal is to store the PV electricity as heat produced by the heat pump in the water storage (TES) or in the building mass (TABS) by overheating the building. However, this causes several effects to occur which are disadvantageous and reduce the saving effect to varying degrees. These additional heat losses (Losses_TES, Losses_HP) are caused by the higher temperatures in the TES and in the space heating system during building overheating, higher start/stop frequency of the heat pump as well as higher building heat losses (transmission and ventilation) due to the overheating up to $26^{\circ} \mathrm{C}$.

Figure 26 shows two bars for each case. The bars consist of the following components:

- Upper bar (supply side)

- Grid to HP grid electricity supplied to the compressor of the heat pump

- PV to HP electricity supplied by the PV system to the compressor

- Evaporator environmental heat supplied to the evaporator

- Lower bar (demand side)

○ DHW Cond heat from condenser to DHW

- DHW Desup heat from desuperheater to DHW

- Heating TES heat supplied by the TES for space heating

- Heating HP heat supplied by the heat pump directly used for space heating

- Losses TES heat losses of the TES

○ Losses HP heat losses of the heat pump (start/stop losses and thermal losses).

In all cases with building overheating (BUI and BUI+TES), it can be observed that due to the building overheating, the total heat demand is higher compared to the reference case. Nevertheless, the grid electricity consumption is significant lower due to high PV electricity consumption. 
In all cases with TES volume more than 500 liter the losses of the heat pump are significantly lower, which can be explained with a decrease in start/stop frequency.

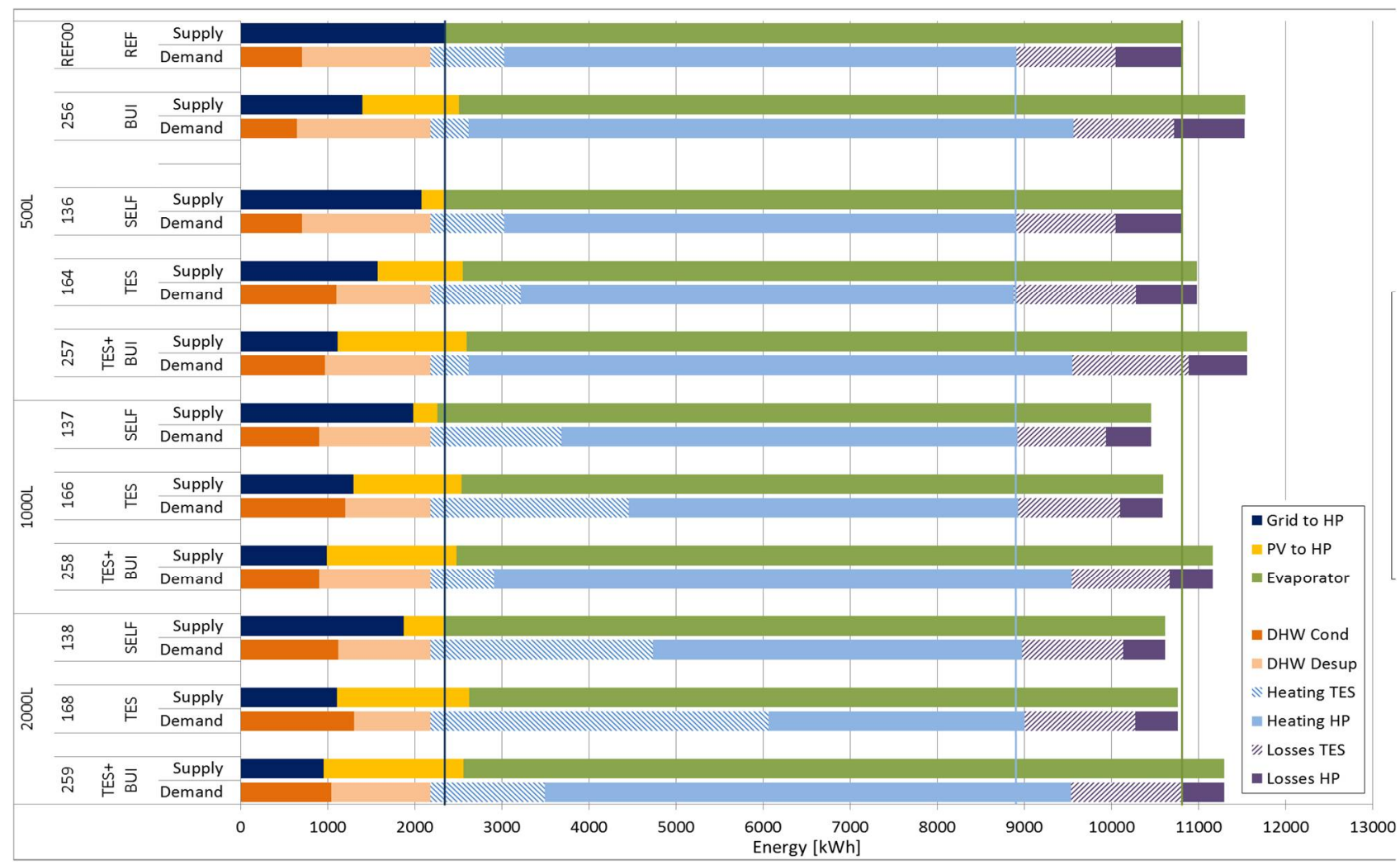

Figure 26 - Energy balances of the building with $20 \mathrm{~m} 2$ PV area, control concepts SELF, BUI, TES, BUI+TES and TES volumes of 500, 1,000 and 2,000 liter.

To examine the effect of the building overheating on the living comfort, the average room temperature during the heating season was used. A sorted chart of the average building temperature can be found in Figure 27 where the changes in room temperatures based on the different control concepts are shown. The temperatures for the control cases TES are similar to those of the reference case, while the results for the BUI+TES cases resemble those of the BUI $26^{\circ} \mathrm{C}$ case.

As can be seen, the average temperature in case of the control strategy BUI+TES is more than $0.5^{\circ} \mathrm{C}$ along the whole year. The reason for this lies in the passive solar gains which, in addition to the delayed heating by the heating system, cause a significant rise in room temperature. This effect also enhances the problems at the highest temperature marks, as the maximum temperature can reach nearly $28^{\circ} \mathrm{C}$ for those cases.

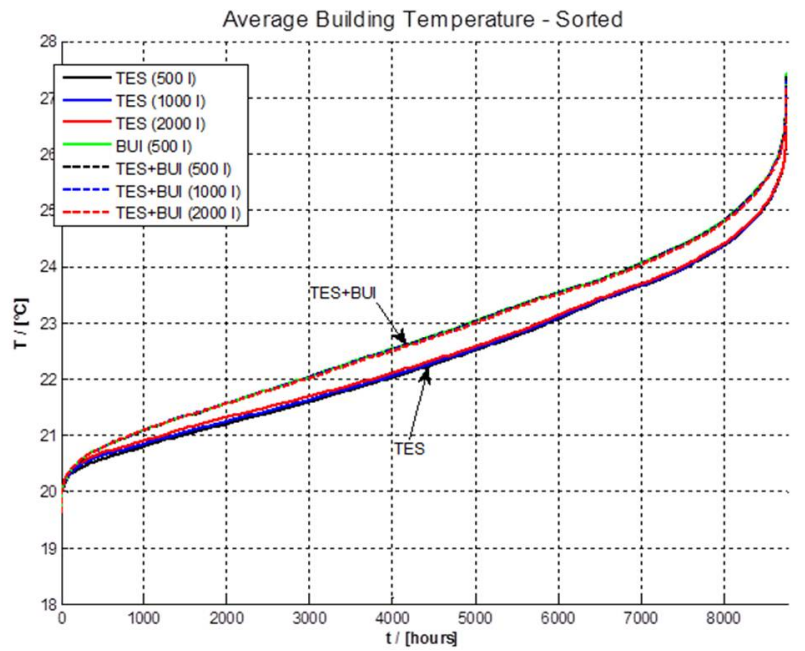




\section{Simulations results for a Reference Multi Family House from the Project HVACviaFaçade}

This chapter reports simulation results of three system concepts simulated within the Austrian project HVACviaFaçade. More detailed information on the project and its results can be found in German language in [5]. The focus of the project was on system concepts for renovation projects where the HVAC system can be integrated as much as possible in the new building façade. The boundary conditions and simulation models are reported in deliverables B1, B3 and B4. The building is a MFH developed in 3 storeys with 4 apartments per storey. Two heating demand levels are studied, 15 and $30 \mathrm{kWh} / \mathrm{m}^{2} \cdot \mathrm{y}$.

The following Table 12 summarizes space heating demand, DHW demand and electricity consumption of the ventilation system for the reference building defined in the project with two different levels of insulation. Space cooling was not considered within the project. The consumption of electrical appliances in the building was assumed to be $16.4 \mathrm{kWh} /\left(\mathrm{m}^{2}\right.$ a). However, the systems were not optimized to cover as much as possible of the household electricity consumption with the PV system. It was only included in the calculation to see how much of it could be covered by excess PV electricity (see section 7.3).

Table 12: Heat demand for space heating, DHW and electricity demand for ventilation

\begin{tabular}{|c|c|c|c|c|c|}
\hline \multirow[t]{2}{*}{ Climate } & $\begin{array}{l}\text { ENERGY } \\
\text { LEVEL }\end{array}$ & $\begin{array}{l}\text { SPACE } \\
\text { HEATING }\end{array}$ & $\begin{array}{l}\text { DHW } \\
\text { PRODUCTIO } \\
\mathrm{N}\end{array}$ & $\begin{array}{l}\text { VENTILATIO } \\
\mathrm{N}\end{array}$ & TOTAL \\
\hline & {$\left[\mathrm{kWh} / \mathrm{m}^{2} \mathrm{y}\right]$} & {$\left[\mathrm{kWh} / \mathrm{m}^{2} \mathrm{y}\right]$} & {$\left[\mathrm{kWh} / \mathrm{m}^{2} \mathrm{y}\right]$} & {$\left[\mathrm{kWh} / \mathrm{m}^{2} \mathrm{y}\right]$} & {$\left[\mathrm{kWh} / \mathrm{m}^{2} \mathrm{y}\right]$} \\
\hline \multirow[t]{2}{*}{ Graz, Austria } & 15 & 14.1 & 26.7 & 3.4 & 43.0 \\
\hline & 30 & 28.9 & 26.7 & 0.7 & 56.3 \\
\hline
\end{tabular}

Three different system concepts were studied. In the first system concept, a central outdoor air heat pump delivers heat for both space heating and domestic hot water. In the second concept, there is a separate outdoor air heat pump installed for each apartment. These heat pumps can be integrated in the façade. The third system uses electricity directly for space heating using infrared panels and to heat a domestic hot water store in each apartment. All systems can be coupled with PV panels installed in the east and west façades as well as in the roof in case of the direct electrical heating systems that consumes more energy. The simulated PV areas are summarized in Table 13. More details on the system concepts can be found in deliverable B3. The difference on the small PV field between the centralized and the decentralized cases lies on the fact that for the first case, the total area corresponds to the available surface of the whole building's facades, while for the other cases the total area is the sum of smaller fields referred to each dwelling.

Table 13: Analysed system concepts, with different PV area sizes, (no PV, small and large PV area)

\begin{tabular}{llll}
\hline & \multicolumn{2}{l}{ PV area $\left[\mathrm{m}^{2}\right]$} \\
\cline { 2 - 4 } & No PV & Small & large \\
\hline Central heat pump & 0 & 191 & - \\
Heat pump in each apartment & 0 & 176 & - \\
Direct electrical heating & 0 & 176 & 419 \\
\hline
\end{tabular}




\subsection{Final and Primary Energy}

Figure 28 shows the final energy consumption of all three system concepts and both energy levels - all without PV system. The amount of final energy necessary for the mechanical ventilation system as well as the final energy used for space heating and domestic hot water are shown. The energy level 15 building includes a mechanical ventilation system with heat recovery whereas the energy level 30 building assumes only an exhaust air system without heat recovery and inlet air through window air inlets. This kind of system consumes considerably less electricity. The final energy consumption is higher for the direct electrical heating system being roughly double. The heat pump solutions consume considerably less energy due to the performance factor of the heat pumps. The system with a separate heat pump for each apartment needs slightly less final energy than the central system. The reason for that is that the distribution losses of the central system for piping between the heat pump and the DHW stores as well as between the buffer store and the apartments are significant. To calculate these losses, the necessary piping lengths in the reference building were analysed in detail.

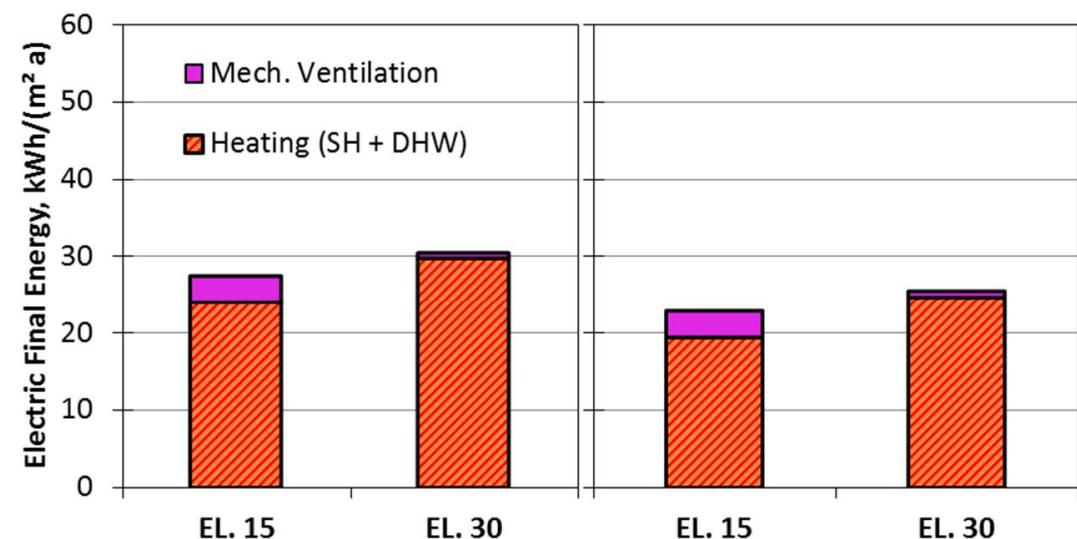

\#1: Central heat pump
\#2: Heat Pump in each apartment

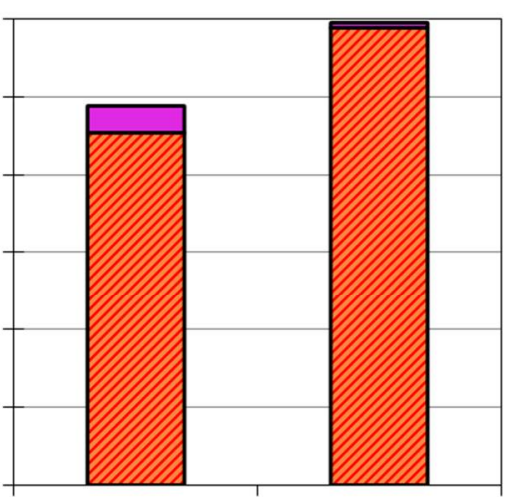

EL. 15

EL. 30

\#3: Direct electrical heating

Figure 28 - Final energy distribution for all three system concepts without PV systems

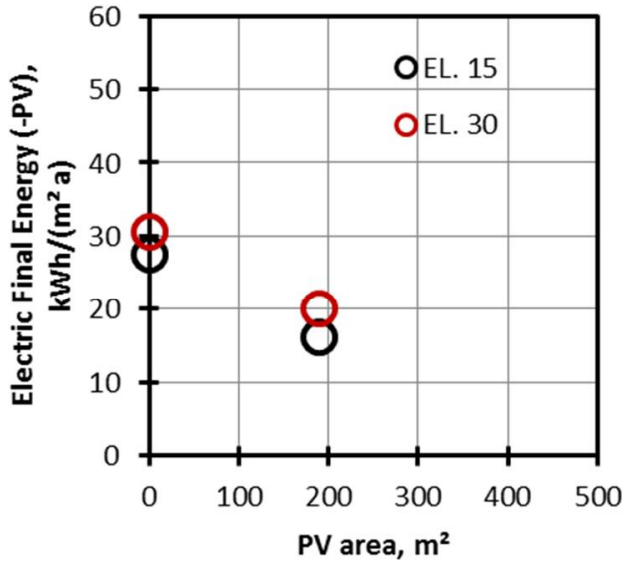

\#1: Central heat pump

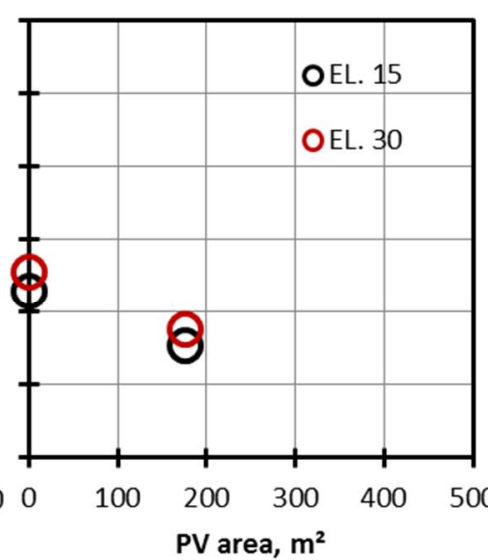

\#2: Heat Pump in each apartment

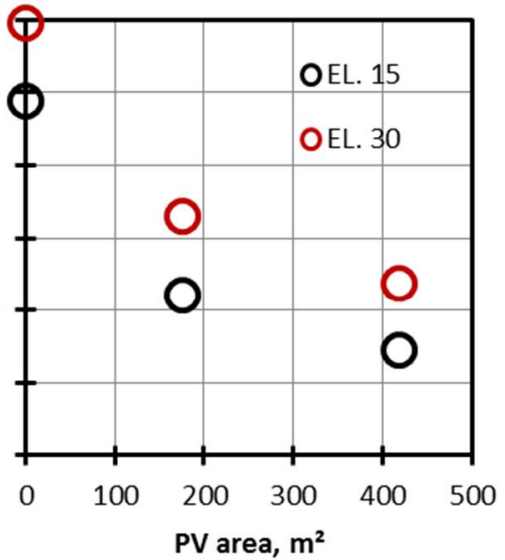

\#3: Direct electrical heating

Figure 29 - Final energy demand for all three system concepts with PV areas, the in-house consumption of PV electricity for HVAC systems is subtracted from the final energy demand

Figure 29 shows the final energy demand as a function of different PV areas. The electricity production of the $\mathrm{PV}$ area is subtracted from the total final energy demand if it can be consumed directly by the HVAC system. Therefore, the final energy demand is reduced significantly with increasing PV area.

The final energy demands of the two heat pump systems are very similar. However, the final energy demand for the system with heat pumps in each apartment is slightly lower than for the central system. The lowest final 
energy demand can be reached with the heat pumps in each apartment and a PV area around $200 \mathrm{~m}^{2}$. Simulations showed that larger PV areas did not reduce the final energy demand significantly.

For the direct electrical heating system, larger PV areas are necessary to reduce the final energy demand to the level of the heat pump systems. For the energy level 15 building around $400 \mathrm{~m}^{2} \mathrm{PV}$ area (which is the maximum available area of the reference building (façade and roof) are just sufficient. For the energy level 30 building, there is not enough area available.

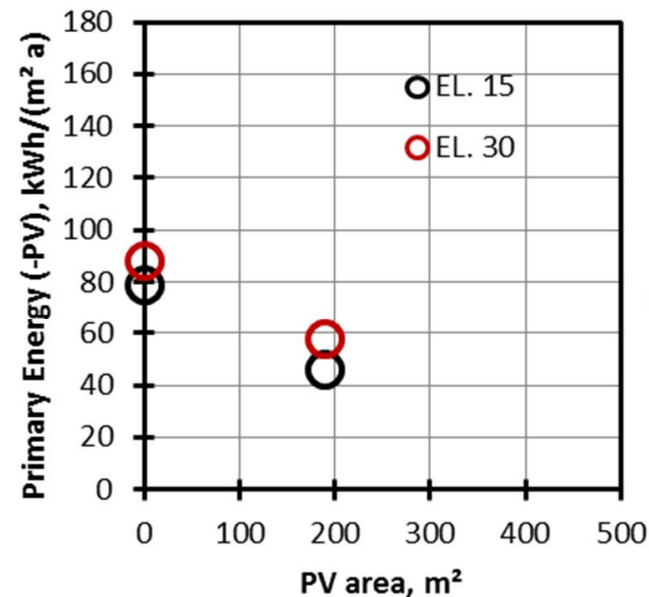

\#1: Central heat pump

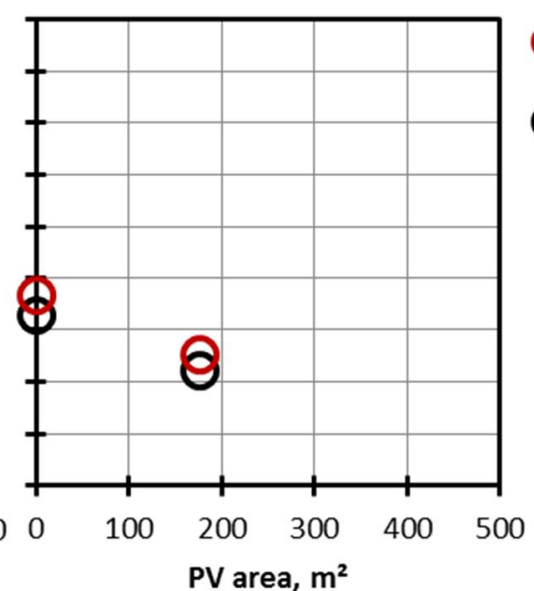

\#2: Heat Pump in each apartment

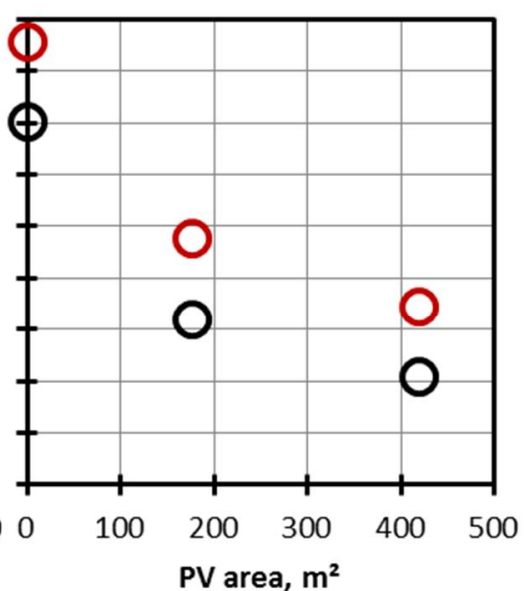

\#3: Direct electrical heating

Figure 30 - Primary energy demand for all three system concepts with PV areas, the in-house consumption of PV electricity for HVAC systems is subtracted from the final energy demand

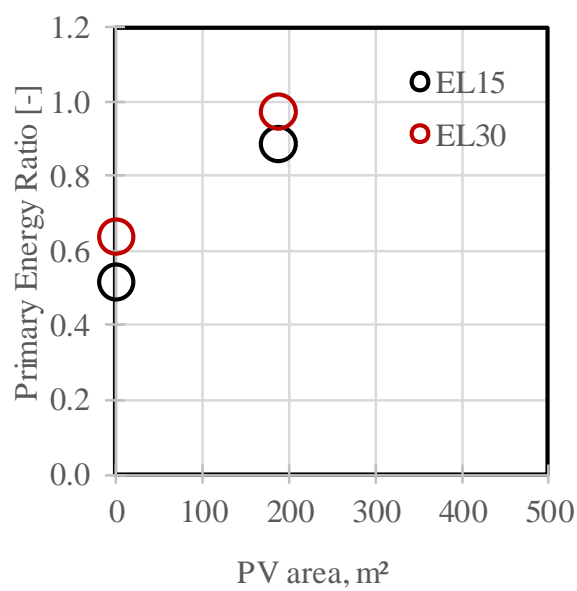

\#1: Central heat pump

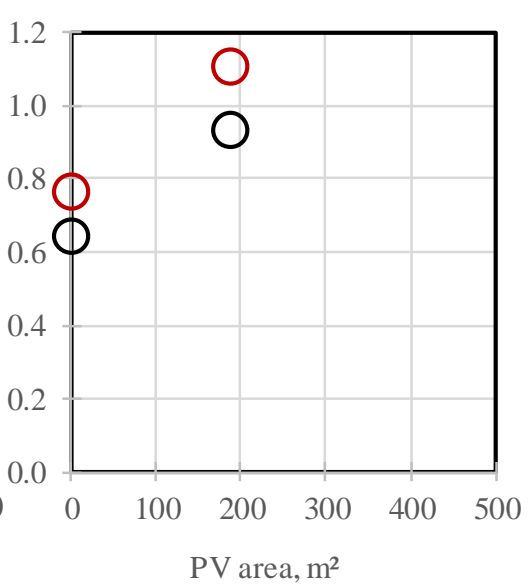

\#2: Heat pump in each apartment

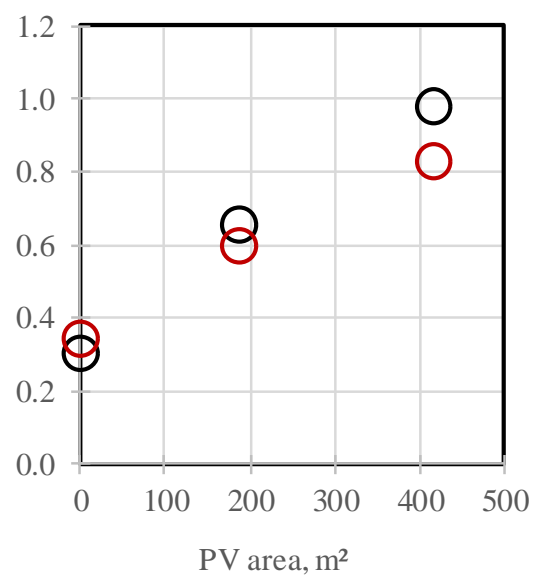

\#3: Direct electric heating

Figure 31 - Primary energy ratio for all three system concepts and PV areas

Figure 30 shows same data as Figure 29 but converted into primary energy. Figure 31 shows the PER for all the cases: the system with a separate heat pump in each apartment shows the best results. Although the absolute primary energy demand is lower for energy level 15 than for energy level 30, energy level 30 shows a higher PER. 


\subsection{Heat Pump and System Performance Data}

The following figure shows performance data of the heat pump in the first two system concepts as well as of the overall system for all three concepts.

The circles show the seasonal coefficient of performance (SCOP) of the heat pumps as defined in chapter 2.2. The SCOP values range from 2.5 to 3 depending on the system type. The red circles mark the results from energy level 30, the black circles for energy level 15. While the SCOP values are almost identical for both energy levels, the values go slightly down from a system without PV generation to the system with $190 \mathrm{~m}^{2}$ of PV. This is because of the higher operating temperatures and part load operation of the heat pump when there is PV electricity available.

In addition, the seasonal performance factor (SPF) is shown in the figure as crosses. This value compares the useful energy for both space heating and DHW with the total final energy consumption of the system including all auxiliary and parasitic electricity consumption as well as the electricity consumption of the ventilation system.
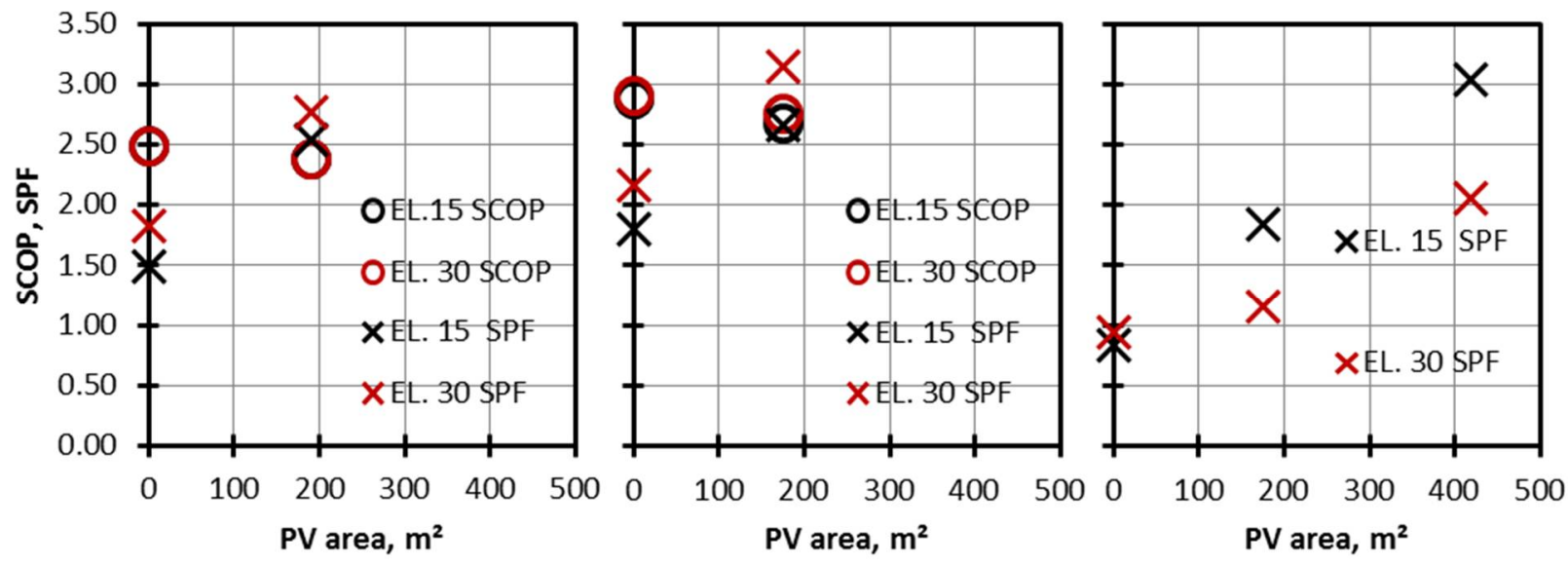

\#1: Central heat pump

\#2: Heat Pump in each apartment

\#3: Direct electrical heating

\section{Figure 32 - Seasonal coefficient of performance of heat pumps (SCOP) and seasonal performance factor of the whole system (SPF)}

For the EL30 building, the best system performance is reached by system \#2 (heat pump in each apartment) with $190 \mathrm{~m}^{2}$ of PV area. However, the building with energy level 15 performs better with the direct electrical heating system and a very large PV area (\#3). The values for the two heat pump systems are only marginally lower with system \#2 (heat pump in each apartment) performing slightly better than the central heat pump system.

\subsection{Performance of PV Systems}

Finally, Figure 33 presents performance results of the PV systems for the simulated cases:

- All three system concepts with roughly $180-190 \mathrm{~m}^{2}$ of PV surface

- System \#3 also with $419 \mathrm{~m}^{2}$ of PV surface

The figure shows the produced electricity divided into the part that is directly consumed by the HVAC system, the part that could be consumed by electrical appliances in the building and the part that is fed into the grid. The evaluation was done on a 5 minutes basis.

As the figure shows, the smaller PV system for the direct electricity concept is chosen far too small, because all electricity is consumed directly by the HVAC system.

For the other three options, the self-consumption by the HVAC systems accounts for roughly one third to one half of the total produced electricity. Considering the consumption of the electrical appliances as well improves the balance slightly. However, there is still a lot of excess PV electricity that has to be fed into the grid. 


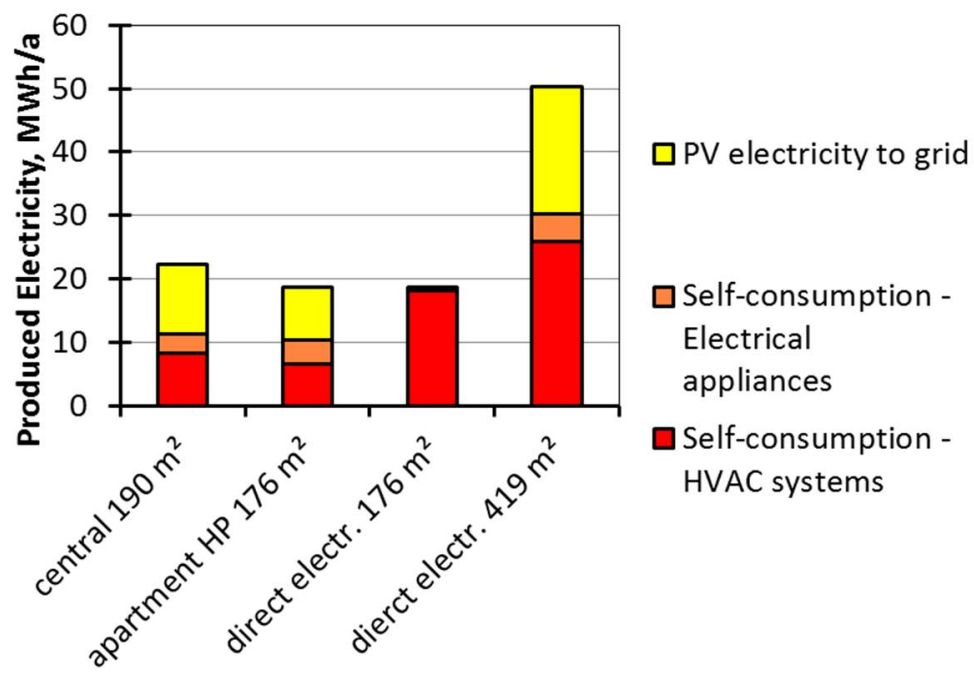

Figure 33 - Produced electricity for different system concepts and PV surface area 


\section{Discussion and conclusions}

The present document reports on the energy performance of a number of combinations of heating and cooling systems with solar thermal and PV fields. The building and climates accounted for are described in deliverable B1, while P\&I diagrams, sizes and control strategies are reported in deliverable B3 and B4.

Table 14 summarises the main results presented in this report: SFH_HP_PV_ST and MFH_HP_PV_ST summarize cases of different PV and solar thermal collector combinations used in combination with a heat pump system in the reference single-family and multifamily houses respectively (sections 3 and 4); SFH_SOR_ST reports results of the solar heating and cooling system in section 5; SFH_HP_PV refers to the PV + heat pump system in section 6, while MFH_HP_DIR_PV refers to the results presented in section 7. The same results are also grouped into charts for easier comparison.

Table 14 - Summary of the performance figures calculated for each presented case

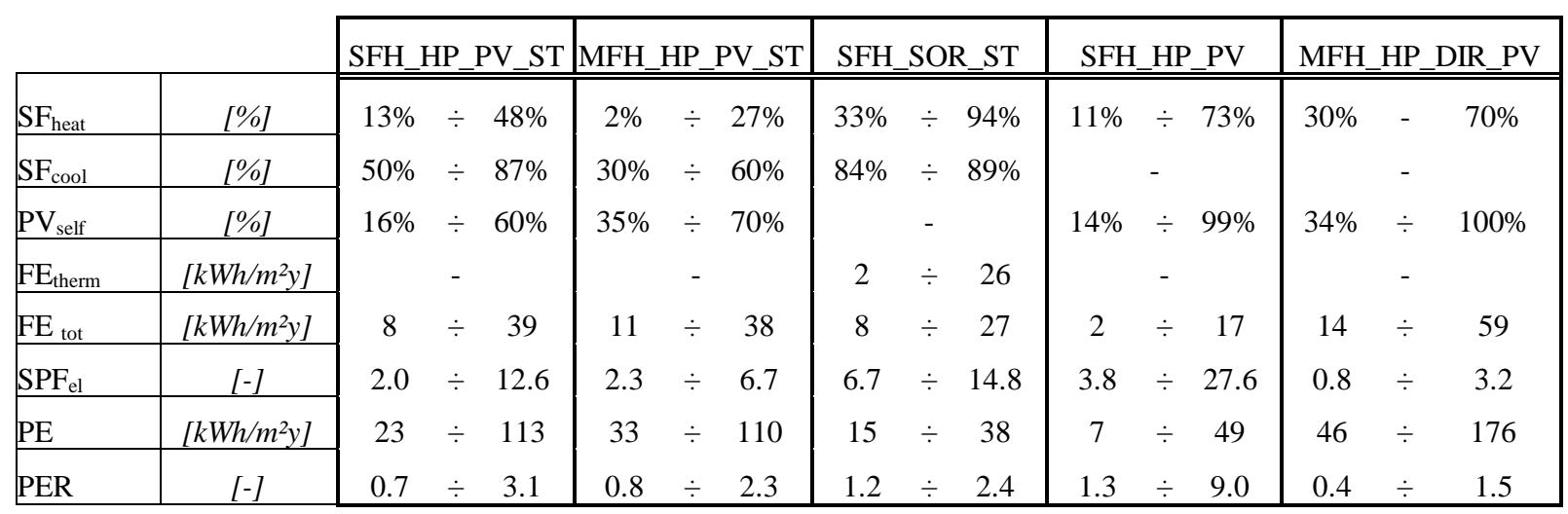

With respect to the reference system (case 1 and 2, SFH_HP_PV_ST and MFH_HP_PV_ST) set up in singleand multifamily houses in Mediterranean and Nordic climates, simulation results show that solar thermal collectors can contribute with 13-48\% to heating uses in SFH (solar field area varying from 4.6 and $13.8 \mathrm{~m}^{2}$ ) and 2-27\% in MFH (solar field area varying from 18.4 and $36.8 \mathrm{~m}^{2}$ ). This difference is related to the lower solar field over heated area ratio in multifamily houses. Despite the lower solar availability of the northern climates, the longer winter season makes the solar contribution significant. In case 3 (SFH_SOR_ST), the solar field is built with evacuated tubes and sized over the cooling load, therefore relevant surface areas are considered (from 24.6 to $44 \mathrm{~m}^{2}$ ). Solar fraction for heating achieves 33\% in the coldest climates and up to $94 \%$ in the warmer ones. SF for heating purposes has been calculated also with respect to case 4 (SFH_HP_PV) clearly with a different definition compared to previous cases: here SF is intended as PV electricity used by the heat pump when produces space heating. Simulations show that, under the boundary conditions analysed, a PV field can reduce the consumption due to the heating loads by $11 \%-73 \%$ (solar field area varying from 20 and $40 \mathrm{~m}^{2}$ ) depending on the PV size and the control strategy implemented to promote the self-consumption of PV electricity. Similarly, solar fraction has been calculated with the same meaning in MFH_HP_DIR_PV: depending on the energy system configuration, the contribution of a PV system can reduce energy consumption for heating purposes from $30 \%$ to $70 \%$. The latest percentage refers to the case of the use of a large PV field coupled with a direct electric heater system.

If space cooling is in focus, the case SFH_SOR_ST shows solar fractions varying from $84 \%$ to $89 \%$ in all climates accounted for, which conversely involves that $11 \%$ to $16 \%$ of the SFH space cooling loads are covered using natural gas. With respect to the SFH_HP_PV_ST and MFH_HP_PV_ST cases, the PV fields accounted for can cut the electricity drawn from the grid for cooling loads from 50\% to around $87 \%$ in SFH and from $30 \%$ to $60 \%$ in MFH. Again, the lower percentage in MFHs is due to the smaller solar fields with respect to the cooled area.

Larger PV fields increase the use of renewable energy for building uses, but the energy fed into the grid increases at the same time. In SFH_HP_PV_ST 16\% to 60\% of the produced PV electricity is used for running the HVAC system, while in MFH_HP_PV_ST the range varies around 35\% to 70\%. Considering also appliances consumption, this percentage increases up to 85-90\% especially in MFHs. 
The percentage of self-consumed PV energy is increased in the fourth case (SFH_HP_PV) thanks to storing excess heat in large TES (thermal energy storage) or in the TABS (thermal activated building system), and by means of dedicated control strategies. In the latter case, it is possible to fully exploit PV electricity by accepting the overheating of the building. Another case of complete self-consumption is verified in case 5 (MFH_HP_DIR_PV) when the generation system is a direct electric heater: using the whole building façade for PV generation is not enough to satisfy the electric load of a EL 30 building, while on the contrary, if a heat pump is used, self- consumption levels again down to $30 \%-40 \%$ are reached.

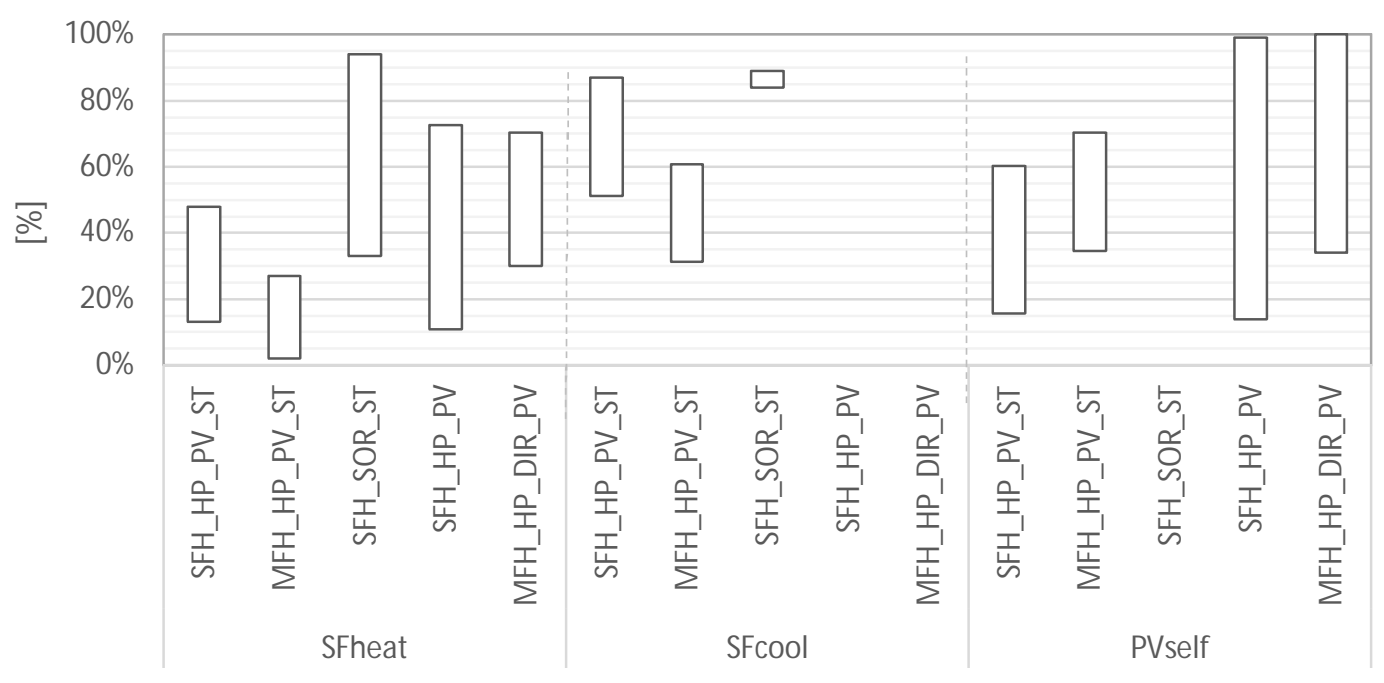

Figure 34 - Solar fraction for heating ( $\left.\mathrm{SF}_{\text {heat }}\right)$, for cooling $\left(\mathrm{SF}_{\text {cool }}\right)$ and $\mathrm{PV}$ self-consumption ratio $\left(\mathrm{PV}_{\text {self }}\right)$ for all cases assessed

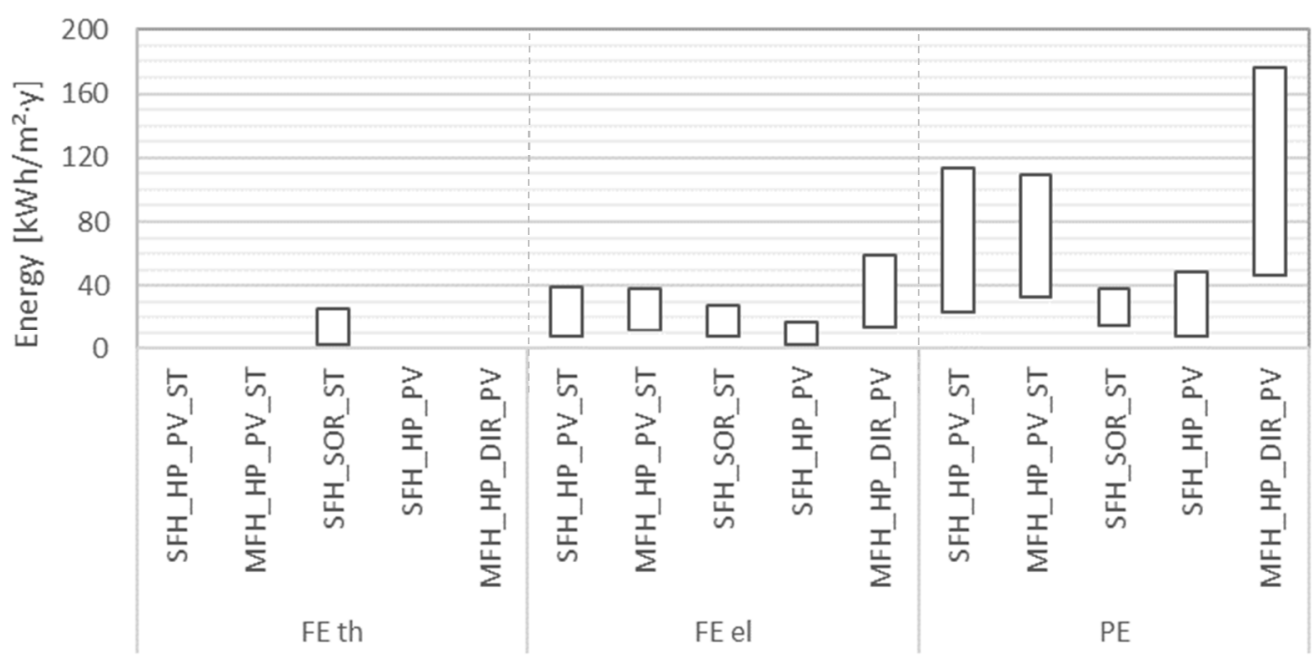

Figure 35 - Thermal final energy ( $\left.F E_{\text {th }}\right)$, electricity consumption ( $F E_{\text {el }}$ ) and Primary energy $(P E)$ for all the studied cases

The specific electric consumption is below $40 \mathrm{kWh} / \mathrm{m}^{2} \cdot \mathrm{y}$ in most of the cases assessed. Indeed case 5 MFH_HP_DIR_PV shows the highest consumption (around $60 \mathrm{kWh} / \mathrm{m}^{2} \cdot \mathrm{y}$ ) due to direct electric heating solutions being considered. In addition to electricity use, natural gas consumption ranging between about 2 and $26 \mathrm{kWh} / \mathrm{m}^{2} \cdot \mathrm{y}$ (from southern to northern applications) shall be associated to the SFH_SOR_ST final energy calculation.

Using solar energy shows quite comparable results when reversible heat pumps and sorption chillers are coupled with ST and /or PV technologies as reduction of about $75 \%$ can be obtained: values down to around $10 \mathrm{kWh} / \mathrm{m}^{2} \cdot \mathrm{y}$. Once more, reaching close-to-zero final energy use requires special strategies to be introduced (see SFH_HP_PV) and both large size thermal energy storage capacity and PV fields. 
Comparing the contribution that solar thermal collectors and PV give to the reduction of the final energy consumption, the effect is similar. A PV system obtains slight better performance if relevant space cooling loads are encountered. Where instead heating loads (both space heating and DHW demand) prevail, energy savings obtained thanks to solar thermal collectors are slightly higher.

When primary energy is calculated, SFH_HP_PV_ST, MFH_HP_PV_ST and MFH_HP_DIR_PV (cases 1, 2 and 5) set the upper boundaries, which correspond to utilisation of reversible heat pumps and electric heaters without any solar contribution. Values between about 110 and $180 \mathrm{kWh} / \mathrm{m}^{2} \cdot \mathrm{y}$ are obtained under these conditions.

The two reference cases 1 and 2, allow to reduce the primary energy use down to $20-30 \mathrm{kWh} / \mathrm{m}^{2} \cdot \mathrm{y}$, the lowest values refer to the coupling of the heat pump with a PV or ST solar field. Particularly effective is the SFH_SOR_ST case which presents low primary energy values (down to $15 \mathrm{kWh} / \mathrm{m}^{2} \cdot \mathrm{y}$ ) thanks to the use of solar energy for covering both cooling and heating loads. The same considerations reported with respect to the SFH_HP_PV final energy consumption reflect on the primary energy, which can be reduced to lower than 10 $\mathrm{kWh} / \mathrm{m}^{2} \cdot \mathrm{y}$.

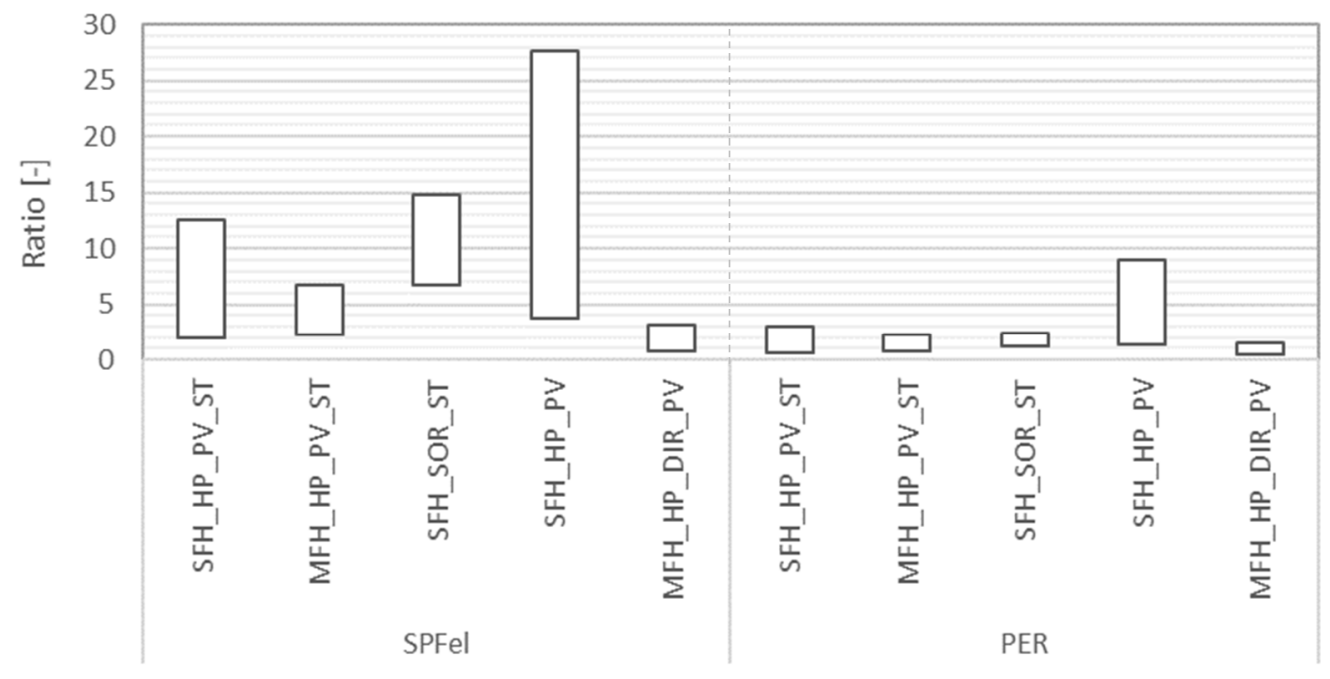

\section{Figure 36 - Seasonal performance factor for electric energy $\left(\mathrm{SPF}_{\mathrm{el}}\right)$ and Primary Energy Ratio (PER) for all the studied cases}

The energy performance of the overall system $\left(\mathrm{SPF}_{\mathrm{el}}\right)$ varies from 2 to 15 when considering systems with heat pump or adsorption chillers and basic control strategies for the utilisation of solar energy are adopted. The best performance is obtained by the solar thermal cooling and heating system as larger surfaces of the solar field are used compared to the overall building loads. On the contrary, more modest outcomes $\left(\mathrm{SPF}_{\mathrm{el}}\right.$ up to 6.7) are encountered with respect to the MFH_HP_PV_ST case due to the lower roof and façade surfaces available to the installation of PV or ST fields.

$\mathrm{SPF}_{\mathrm{el}}$ higher than 25 is verified when excess heat is stored both in large thermal storages and in building thermal mass (SFH_HP_PV). In this last case, the simulations show however as increasing indefinitely the thermal storage size or the overheating of the building rooms does not imply better performance, rather increase the system thermal losses, therefore an optimum is to be found.

Despite the solution with direct electric heater results energetically convenient when coupled with a large PV field, it results in low overall $\mathrm{SPF}_{\mathrm{el}}$ levels.

Finally, the distribution of PER is quite flat and ranges between 0.4 and 3 for all the cases analysed. Only the SFH_HP_PV systems reach PER values up to 9, following the $\mathrm{SPF}_{\mathrm{el}}$ trends.

As a final remark, the studies presented do not permit to identify what technology outperforms the other, as similar results are obtained under different perspective (i.e. key performance indicators) accounted for.

On the other hand, they demonstrate how relevant solar thermal and PV technologies can be in terms of reducing both final and primary energy uses of heating and cooling systems in residential buildings. 
The wise sizing of the solar surfaces with respect to thermal loads and generation units is key to maximise the solar energy utilisation, and self-consumption in case PV panels are considered. However, when close-to-zero fossil energy use is sought, also expert control strategies need to be implemented in order to optimise matching among solar availability, user energy utilisation paths and storages/building thermal capacity. 


\section{References}

[1] Fedrizzi R., Dipasquale C., Bellini A., Gustafsson M., Bales C., Ochs., Demerzentzis G., Nouvel R., Cotrado M. D6.3b Performance of Studied Systemic Renovation Packages - Single Family House. iNSPiRe EU FP7 Project Grant Agreement n 314461, 2015, www.inspirefp7.eu

[2] Fedrizzi R., Dipasquale C., Bellini A., Gustafsson M., Bales C., Ochs., Demerzentzis G., Nouvel R., Cotrado M. D6.3c Performance of Studied Systemic Renovation Packages - Multi Family House. iNSPiRe EU FP7 Project Grant Agreement n 314461, 2015, www.inspirefp7.eu

[3] The Reference Framework for System Simulations of the IEA SHC Task 44 / HPP Annex 38 - Part B: Buildings and Space Heat Load, 2013.

[4] Malenkovic I, Eicher S., Bony J. Definition of main system boundaries and performance figures for reporting on SHP systems- A technical report of Subtask B- Deliverable B1.1. IEA SHC Task 44, HPP Annex 38, 2012

[5] Christian Fink et al. (2017): Final Project Report: Vorgefertigte Fassadenelemente mit maximal integrierten HVAC-Komponenten und -Systemen zur Bestandssanierung (in German), Austrian Klima- und Energiefond, Project number: 843945

Note : the IEA SHC Technology Collaboration Programme (IEA SHC TCP) functions within a framework created by the International Energy Agency (IEA). Views, findings and publications of the IEA SHC TCP do not necessarily represent the views or policies of the IEA Secretariat or of its individual member countries. The IEA SHC TCP and the IEA make no representation or warranty, express or implied, in respect of this paper's content (including its completeness or accuracy) and shall not be responsible for any use of, or reliance on, the paper. 